\title{
Effects of intra-vineyard variability and soil heterogeneity on vine performance, dry matter and nutrient partitioning
}

\author{
Matteo Gatti ${ }^{1,2}$ (D) Alessandra Garavani ${ }^{1,2}$. Cecilia Squeri ${ }^{1} \cdot$ Irene Diti ${ }^{1}$ (D) \\ Antea De Monte ${ }^{3} \cdot$ Carla Scotti $^{3} \cdot$ Stefano Poni ${ }^{1,2}$ (D)
}

Accepted: 13 July 2021 / Published online: 27 July 2021

(c) The Author(s) 2021

\begin{abstract}
Three vigor zones, identified in a Barbera vineyard by remote sensing at full canopy, were carefully ground-truthed to determine, over 2 years, the relative weight of soil factors in affecting within-field variability, and to investigate vigor zone influence on dry matter (DM) and nutrient partitioning into different vine organs. Regardless of season, high vigor (HV) achieved stronger vine capacity as total vegetative growth and yield while resulting in markedly less ripened fruits than low vigor (LV) vines. PCA analysis carried out on ten different soil and vine variables clearly separated the three vigor levels and the correlation matrix highlighted that the factors mostly contributing to $\mathrm{HV}$ were soil depth, soil $\mathrm{K}$ and $\mathrm{P}$ concentration, total available water, clay fraction and $\mathrm{N}_{\text {leaf }}$ concentration. Conversely, sand fraction was the main marker for LV. When annual DM retrieved in clusters, canes, leaves, and shoot clippings was calculated for each vigor level and expressed as content (i.e. $\mathrm{kg} /$ ha) there was a general decreasing trend moving from HV to LV. However, when DM partitioned to each organ was given on a relative basis (i.e. percentage over total) results were similar across vigor levels. Similarly, when nutrients were given as content (e.g. $\mathrm{kg}$ or g/ha) out of 120 within-vigor combinations (12 nutrients, 2 seasons, 5 organs), 65 showed a significant difference between HV and LV. Conversely, with data expressed on a concentration basis (i.e. \% DM) the number of significant differences between the vigor level means fell to 15 . The study strengthens the causal link between soil properties and intra-vineyard spatial variability and clarifies that patterns of dry matter and nutrient partitioning to different vine organs are mildly affected by vine vigor when referred on a relative basis.
\end{abstract}

Keywords Terroir $\cdot$ Spatial variability $\cdot$ Mapping $\cdot$ Precision viticulture

Matteo Gatti

matteo.gatti@unicatt.it

1 Department of Sustainable Crop Production (DI.PRO.VE.S.), Università Cattolica del Sacro

Cuore, Via Emilia Parmense 84, 29122 Piacenza, Italy

2 Remote Sensing and Spatial Analysis Research Center (CRAST), Università Cattolica del Sacro Cuore, Via Emilia Parmense 84, 29122 Piacenza, Italy

3 I.Ter Soc. Cooperativa, Via E. Zacconi 12, 40127 Bologna, Italy 


\section{Introduction}

The simplest definition of terroir is the way the vineyard environment shapes grape and wine quality and uniformity of ripening is still one of its main components (Deloire et al., 2005). Indeed, balanced vegetative growth and a non-limiting or controlled leaf area-tofruit ratio play a key role in ripening uniformity and, over the past decades, several changes or innovations brought into the vineyard have aimed to increase uniformity. Among them, improved soil preparation to minimize patchiness, healthier propagating material and new clones to assure higher yield stability, adoption of a short pruning approach to mitigate the steep gradients of growth and vigor observed under cane pruning and a wiser use of summer pruning operations stand out as the most important (Poni et al., 2018). A good way to exemplify the meaning of "uniformity of ripening" is having two different grape batches of equal size (i.e. 300 berries) that, after crushing, would yield a must with a very similar total soluble solids concentration (TSS) (i.e. 24 Brix). However, if each single berry was processed for TSS, the resulting Gaussian distribution might likely present different variances $\left(\sigma^{2}\right)$ and including varying dispersions around the mean. With increasing variance, but a fixed mean, the contribution of both immature and over-ripe berries would increase and alter the traits of the final wine. The same concept holds true for either within-cluster, within-vine and within-vineyard variability and also explains why "variability" has been traditionally regarded as a negative feature in vineyard management (Dai et al., 2011).

The advent of precision agriculture (Pierce \& Nowak, 1999) including the most recent vineyard applications (Bramley \& Hamilton, 2004; Matese \& Di Gennaro, 2015; Tisseyre et al., 2008) allowed an increasing availability of powerful sensing tools, which are currently able to scan the vineyard under remote or proximal modes (Maes \& Steppe, 2019; McBratney et al., 2005). These are able to provide vigor, yield and grape quality maps at exceptionally high ground resolution, raising the prospect that the so much feared "withinvineyard variability" might turn itself into an unexpected ally to achieve higher vineyard efficiency. Starting late in the 1990s, a multitude of studies have investigated intra-vineyard spatial variability using vegetation indices and a fairly common trait of several studies has been that, regardless of vineyard size and image ground resolution, significant spatial variability in the vegetation indices has been linked to vine performance (Bramley et al., 2011; Gatti et al., 2017; Matese \& Di Gennaro, 2015; Rey et al., 2013). It has been repeatedly reported that different vigor zones within the same vineyard can achieve largely different crop levels and, in turn, varying grape composition at harvest. Bramley et al. (2005) have confirmed that contrasting wines might derive from different areas within the same, uniformly managed vineyard. This outcome shifted the terroir focus from a broad regional scale to a single vineyard level (Vaudour et al., 2015) paving the way to either exploitation or correction of current variability towards the desired level (Gatti et al., 2018, 2020). However, the latter approach can be implemented if a few issues are clarified to include (i) temporal (i.e. year to year) stability of the effects due to spatial variability; (ii) nature and primary factors involved in determining spatial variability and (iii) grapevine sensitivity (e.g. yield and specific grape components) to spatial variability.

Evidence has been provided (Bramley \& Hamilton, 2004; Johnson, 2003; Kazmierski et al., 2011; Willwerth \& Reynolds, 2020a, b) that relative differences among management zones identified within a vineyard tend to be relatively stable over time. Such stability links to a strong controlling factor that is usually associated with soil heterogeneity (Priori et al., 2019). Focusing on Marlborough Sauvignon blanc, Bramley et al. (2011) showed that the highest yielding zones frequently match with deepest soil horizons leading to an increase in 
the amount of available water. Similar results were also found by Tardaguila et al. (2011). Among other soil features, organic matter content, salinity and texture have proven to be important factors to differentiate within-vineyard management zones (Baluja et al., 2013; Bramley \& Lamb, 2003; Tardaguila et al., 2011; Trought et al., 2008).

Assuming that within-vineyard spatial variability of a uniformly managed vineyard is quite constant over time as being primarily bound to soil features, which are unlikely to change in the medium term, then it would be interesting to evaluate, for single vine parameters, stability of their spatial distribution patterns. Some work (Baluja et al., 2013; Bramley et al., 2005; Tisseyre et al., 2008; Trought \& Bramley, 2011) has overall validated the hypothesis that while yield spatial distribution patterns tend to be relatively stable from year to year, the structure of the spatial distribution of key grape quality parameters does not necessarily agree with the spatial yield distribution pattern. In vineyards characterized by relatively balanced conditions corresponding to "medium vigour" zones, a sort of expected behavior would predict that a so called "high vigor" area would also have higher yield and quite retarded or incomplete ripening, whereas the "low vigor" zone is supposed to link to lower yield and full ripening with overall better wine quality (Arnò et al. 2012; Hall et al. 2011). However, the literature reports large deviations from such a predicted scenario; cases in point are those reported by Fiorillo et al. (2012) and by Bonilla et al. (2015) who mapped a Sangiovese and a Tempranillo vineyard in Tuscany (Italy) and La Rioja (Spain) regions, respectively. In both papers, it is shown that the so called "high vigor" plot, declared as such on a pruning weight basis, was actually the one assuring the best quality, especially in terms of berry total anthocyanins concentration. The explanation given was that both environments experience hot summers with several heat spells conducive to berry overheating and sunburn. Under such conditions, a high vigor status is more favorable to cluster protection from direct radiation, having well known positive effects on color synthesis while also limiting degradation of already formed color, which is largely enhanced at air temperatures above $35^{\circ} \mathrm{C}$ (Mori et al., 2007). Concurrently, high vegetative vigor does not always mean a higher yield; an instructive example has been provided by Bramley et al. (2011) that, in a Sauvignon blanc vineyard in Marlborough (NZ), showed that vines labeled as "high vigor" due to extra-size trunk circumference did show retarded ripening as lower TSS and higher TA; however, the same extra size vines did not achieve any yield increase as compared to small size vines. The above findings sound like a double warning: (i) in addition to yield maps, any within-field zoning of grape quality may require inclusion of other crop, soil and/or environmental parameters, and (ii) simple "labeling" of vigor areas without site-specific ground-truthing can lead to meaningless or even deceptive information.

Thus, ground-truthing seems to be a key element to validate the various vegetative indices that may be derived from the processing of images. However, attention given to a ground-truthing protocol seems to be less careful than that devoted, for instance, to the statistics of image acquisition or the post processing of the acquired data (Khaliq et al., 2019; Matese et al., 2015; Squeri et al., 2021a) and, when undertaken, limited to quite basic yield and grape quality components (Bramley et al., 2011; Fiorillo et al., 2012; Gatti et al., 2017; Tisseyre et al., 2008). For instance, once a given vigor map is produced, there is rarely any local follow on work to understand how differential vigor of the different homogeneous zones will affect dry matter and nutrient partitioning to the different vine organs and, in turn, final grape and wine quality.

The objectives of this study were to: (i) determine relative weight of soil factors affecting spatial variability in vegetative growth, yield components and grape quality parameters of a cv. Barbera vineyard previously mapped through satellite imagery, and (ii) extend 
ground-truthing of different vigor zones to dry matter and nutrient partitioning to different vine organs.

\section{Material and methods}

\section{Plant material, vigor maps and experimental layout}

The study encompassing a 2-year characterization of plant behaviours and a later soil survey was performed between 2016 and 2019 in a commercial vineyard block located in the Malvicini Paolo Estate in the Colli Piacentini wine district $\left(44^{\circ} 98^{\prime}\right.$ N, $9^{\circ} 36^{\prime}$ E, $272 \mathrm{~m}$ a.s.1.). According to the Soil Map of Emilia-Romagna at 1:50,000 scale (Regione EmiliaRomagna, 2018), the site mainly falls within the Vicobarone soil series (VCB) Map Unit (Consociation of the "Vicobarone" clayey; 15-20\% slopes), delineation number 8763, with the following secondary soils: Montalbo (MNB1) and Sala Mandelli (SMD). However, a small part of the vineyard falls in the MNB1 Map Unit (Consociation of the "Montalbo" clayey; $15-20 \%$ slopes), delineation number 8753 , that is mostly represented by Montalbo (MNB1) and Sala Mandelli, (SMD) soils series.

The 1.2 ha vineyard block was established in 2011 on an east-facing $15 \%$ slope with vines planted $1.2 \mathrm{~m}$ within and $2.5 \mathrm{~m}$ between rows for a resulting density of 3333 vines/ ha. East-West oriented rows of mature Vitis vinifera L. cv. 'Barbera' vines grafted on Kober 5BB rootstock were single cane pruned and trained to a vertical shoot positioning system; the horizontal support wire was fixed at $0.9 \mathrm{~m}$ above the ground and three catching wires were used for building a canopy wall of, or approximately, $1.5 \mathrm{~m}$ above the supporting wire. Vineyard management was carried out according to the regional protocol for sustainable agriculture encompassing no summer irrigation, canopy trimming (normally carried out after fruit-set), and fruit-zone leaf plucking by removing leaves from the northfacing side of the canopy prior to harvest ( 18 Brix). Native cover crops were alternated to soil tillage every second row whilst within-row space was managed by an early-spring glyphosate application on a $0.6 \mathrm{~m}$ wide strip. During each season, daily minimum, mean and maximum temperatures $\left({ }^{\circ} \mathrm{C}\right)$, and total precipitation $(\mathrm{mm})$ were recorded by a weather station located within the vineyard.

Within-field vineyard variability was measured in July 2014 by satellite imagery at $5 \mathrm{~m}$ ground resolution and represented by an NDVI map as previously reported by Gatti et al. (2020). Based on an equal-area algorithm, the vigor map was then partitioned into three vigor classes namely low (LV), medium (MV) and high (HV), corresponding to the NDVI ranges $0.276-0.329,0.290-0.382$ and $0.382-0.435$, respectively (Fig. 1). Thereafter, three blocks were identified within the vineyard and, for each vigor $\times$ block combination, four sentinel vines were tagged and assumed as sub-replicates for subsequent determinations.

\section{Soil survey}

In May 2018, nine sampling points located between two adjacent rows were identified by considering the remotely-sensed vigor areas, the most representative soil-to-landscape relationships at 1:50,000 scale (Regione Emilia-Romagna, 2018) and several topographic observations, such as slope, elevation, aspect and water flow direction. For each point, geographic co-ordinates were recorded by using an accurate GNSS device GPSMAP 62 STC (Garmin Ltd, Canton Schaffhausen, Switzerland). At the nine sampling points, soil 


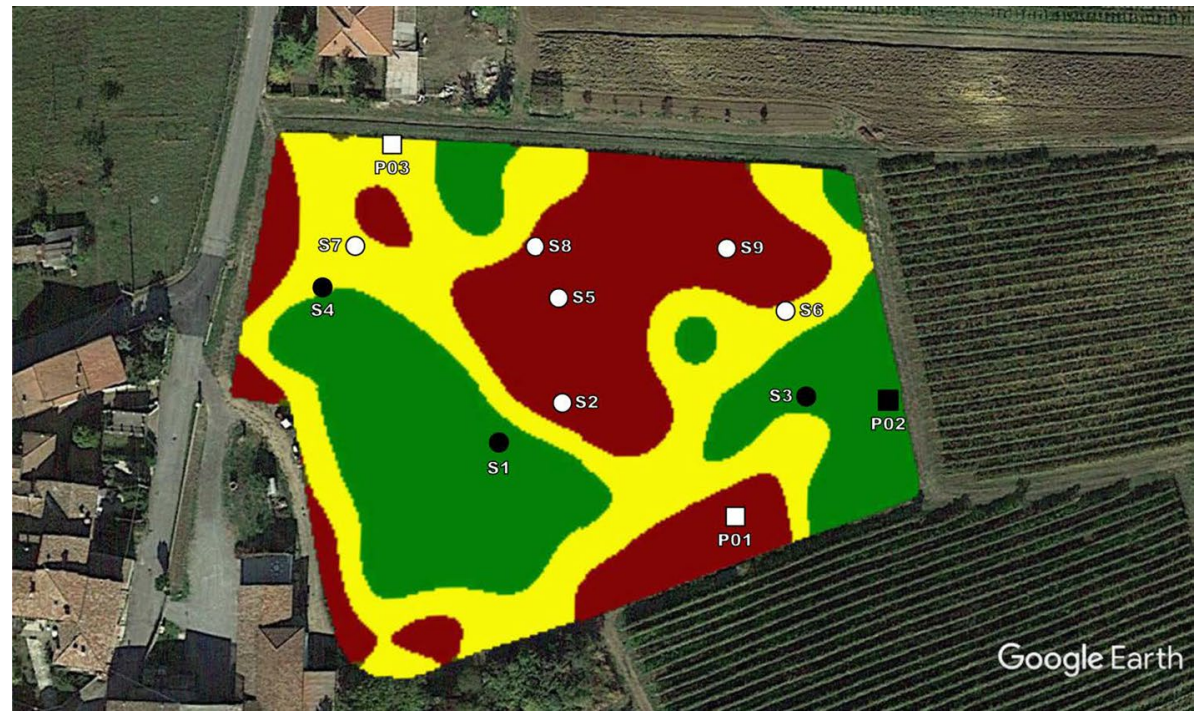

Fig. 1 Location and coding of auger-based soil inspections (circles) and soil profile diggings (squares) carried out within the experimental vineyard. Data are overlapped to the NDVI map and classified according to the Soil Map of Emilia-Romagna Region. Indicators corresponding to VCB and MNB1 soil types are black and white colored, respectively. Green, yellow and red colours correspond to high, medium and low vigor zones

coring was carried out down to $1.20 \mathrm{~m}$ depth by using a Dutch auger. Depending on the preliminary auger-based soil assessment and the NDVI map, three representative subareas were identified within the HV, MV and LV zones and the corresponding soil profiles were opened on the 17 July, 2019. According to the regional protocol for soil description (Regione Emilia-Romagna, 2002), a mechanical digger was used to excavate a $1.2 \times 2.5 \mathrm{~m}$ open pit down to $1.40 \mathrm{~m}$ depth or until reaching the bedrock horizon (R). For each horizon and pit, a representative soil sample was collected and sent to an external laboratory for determining the main chemical and physical properties: texture (sand, silt and clay according to the following grain size ranges 2000-2050, 50-52 and $<2 \mu \mathrm{m}$, respectively), reaction ( $\mathrm{pH}$ in water), total lime (volumetric method), active lime (Droineau), organic matter (by elemental analysis), total nitrogen (Kjeldhal), exchangeable P (Olsen) and exchangeable K (ammonium acetate method). Auger- and pit-derived soil observations were linked to soil types described by the regional Soil Map of Emilia-Romagna (2018) and classified up to the family level according to the Keys of Soil Taxonomy (Soil Survey Staff, 2014) and the World Reference Base 2014 (IUSS Working Group WRB, 2015).

\section{Vegetative growth}

In 2016 and 2017, when canopy growth was completed, four additional vines were identified per each vigor $\mathrm{x}$ block combination and one representative cane per vine was totally defoliated by keeping separate main and lateral leaves. Collected samples were then taken to the laboratory where each leaf blade was individually scanned with a leaf-area meter (LI-COR 3000 Bioscience, Lincoln, NE) and the mean area calculated. After leaf fall, in both experimental seasons, the total number of nodes was counted on each sentinel vine 
by considering the contribution of main and lateral shoots. Accordingly, leaf area per vine (LA) was calculated by multiplying the node count for the corresponding leaf area. Winter pruning was carried out on the 6 December 2016 and the 4 December 2017; at that time pruning weight for main and lateral 1-year old canes was quantified by using a portable field-scale. Vine balance was then calculated on a vine basis as the leaf area-to-fruit ratio $\left(\mathrm{m}^{2} / \mathrm{kg}\right)$.

\section{Nutritional status}

Leaf nutritional status was assessed at veraison in both 2016 and 2017 seasons on 28 and 26 July, respectively. For each vigor $\times$ block combination, 50 mature opposite-to-cluster basal leaves were sampled from mid-vigor shoots as described by Bavaresco et al. (2010). Petioles were removed and blades washed twice in $2 \%$ sodium hypochlorite solution, rinsed twice in distilled water and dried at $75^{\circ} \mathrm{C}$ until a constant weight. Subsequently, dry tissue was ground to a very fine powder and samples were sent to the laboratory for determination of $\mathrm{N}, \mathrm{P}, \mathrm{K}, \mathrm{Mg}, \mathrm{Ca}, \mathrm{S}, \mathrm{Fe}$ and $\mathrm{B}$.

\section{Yield components and fruit composition}

In 2016 and 2017, shoot fruitfulness was determined on a vine basis at BBCH 53 (Lorenz et al., 1995) as inflorescence-to-shoot ratio. Harvest was undertaken 19 September 2016 and 29 August 2017 at technological maturity (i.e. TSS ranging between 22 and 23 Brix and titratable acidity $<10 \mathrm{~g} / \mathrm{l}$ ) corresponding to optimal sugar-to-acidity ratio for the target wine style (Nogales-Bueno et al., 2014); from each sentinel vine all clusters were counted, and their total weight immediately recorded with a portable scale. Biochemical and morphological assessment was then undertaken on three clusters per tagged vine, that were individually weighed and rachis length measured to calculate a compactness index (Tello \& Ibáñez, 2014), which is given as total berry fresh mass/rachis plus main shoulder length ratio $(\mathrm{g} / \mathrm{cm})$. From each sample, a 50-berry subset was used for determining total anthocyanins and phenolics concentration (Iland, 1988). Remaining grapes were crushed and the resulting juice was immediately processed for the determination of total soluble solids (TSS) through a temperature-compensating refractometer (RX-5000 ATAGO U.S.A., Bellevue, WA, USA), must-pH with a pH-meter CRISON GLP 22 (Crison, Barcelona, Spain), and titratable acidity (TA) by titration with $0.1 \mathrm{~N} \mathrm{NaOH}$ to a $\mathrm{pH} 8.2$ endpoint and expressed as $\mathrm{g} / \mathrm{l}$ of tartaric acid equivalents. Tartrate and malate concentration was determined by chromatography (Savi et al., 2019).

\section{Dry weight and nutrients partitioning}

In both the experimental years 2016 and 2017, destructive samples were collected through the season in order to determine dry weight and nutrient partitioning among different vine organs. Fresh biomass was removed prior to canopy trimming on 22 June and 2 August 2016 and 7 June and 4 August 2017, simulating the cutting profile of the tractor-mounted cutter bars used by the grower. Immediately after harvest, the whole canopy of each tagged vines was enclosed in a $1 \mathrm{~cm}$ mesh netting until the end of leaf fall in order to intercept all leaves upon their drop. In each block of different vigor zones, fresh biomass of different vegetative organs (shoot clippings at trimming, leaves shed at fall, 1-year old canes 
removed at winter pruning) were collected from the four sentinel vines and compounded in a single pooled sample. Similarly, 60 berries per tagged vine were randomly collected and composed into a 240-berry sample for each vigor $\times$ block combination. All the samples were dried in a forced-air oven at $105{ }^{\circ} \mathrm{C}$ until a constant weight, ground to a fine powder in a Model 4 Wiley mill (Thomas Scientific, Swedesboro, NJ, USA), and processed for mineral elements determination as previously described. According to Iandolino and Williams (2014), annual uptake of macro (N, P, K, Mg, Ca, S) and trace (Na, Fe, Mn, Za, $\mathrm{Cu}, \mathrm{B})$ elements was calculated as the product of their concentration in different organs (expressed on a dry weight basis) and the corresponding amount of dry matter for clusters at harvest, 1-year-old canes at winter pruning, shoots clippings at trimming and leaves at fall.

\section{Statistical analysis}

Data on vine performance were subjected to a two-way ANOVA using the IBM SPSS Statistics for Windows, Version 25.0. (IBM Corp, Armonk, NY, USA). Vigor (V) was assumed as being a fixed factor and year (Y) was considered as a random variable. The $\mathrm{F}$ test significance mean values were compared by Student-Newman-Keuls test at $5 \%$ probability. When significant in the ANOVA, vigor $\times$ year interactions $(\mathrm{V} \times \mathrm{Y})$ were partitioned and mean values compared by standard error. Data on annual biomass and mineral uptake were subjected to a one-way ANOVA and, in the case of F test significance, vigor classes were compared by Student-Newman-Keuls test at 5\% probability. Due to the high number of measured variables that might have contributed to spatial variability, a principal component analysis (PCA) was also carried out using the XLSTAT statistical package (Addinsoft, New York, NY, USA). Observations were single block data for 10 selected parameters representative of soil properties, texture, macro-element supply and leaf $\mathrm{N}$ concentration. The chosen PCA was a Pearson correlation matrix, number of filter factors was set at 5 and the final data visualization was in the form of a distance bi-plot.

\section{Results}

\section{Seasonal weather trends}

In 2016, cumulated growing degree days (GDD) from April to October on a $10{ }^{\circ} \mathrm{C}$ base temperature were $1944{ }^{\circ} \mathrm{C}$ and annual precipitation was of $758 \mathrm{~mm}$ (Fig. S1). The 2017 season was warmer and drier as compared to the first trial year as GDD summed up to $2143{ }^{\circ} \mathrm{C}$ and annual precipitation was $493 \mathrm{~mm}$. Despite seasonal precipitation from April to September being almost equivalent in the 2 years (288 $\mathrm{mm}$ on average), in 2016 abundant precipitation occurred in May and June ( 85 and $95 \mathrm{~mm}$, respectively) while, in 2017, a significant decrease in precipitation was registered from the end of May and coupled to very high thermal regimes that frequently picked up to $36-37^{\circ} \mathrm{C}$ between June and August.

\section{Soil description}

The soil profile corresponding to HV revealed the following traits: very deep soil, moderately drained, clayey with vertic characteristics; four different layers were described down to $1.40 \mathrm{~m}$ depth (Fig. 2 and Table S1). The soil properties in the Ap-horizons 


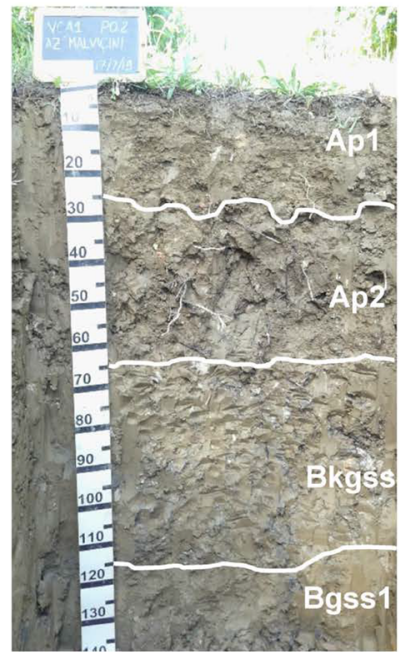

1Vicobarone Soil (VCB), clayey with $15-20 \%$ slope grade

${ }^{2}$ Vertic Haplustepts fine, mixed, superactive, mesic

${ }^{3}$ Vertic Cambisols (Colluvic)

\section{${ }^{4}$ High Vigour}
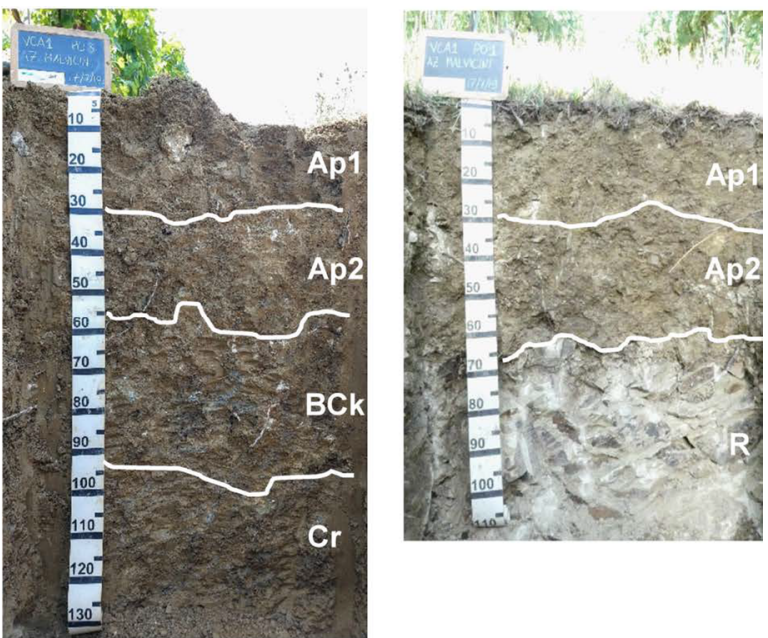

\begin{abstract}
1Montalbo Soil (MNB1), clayey with $15-20 \%$ slope grade
\end{abstract}

2Typic Ustorthents fine, mixed, active, calcareous, mesic

${ }^{3}$ Eutric Regosols (Clayic)

\section{1'Montalbo Soil (MNB1), clayey with $15-20 \%$ slope grade}

${ }^{2}$ Typic Ustorthents fine, mixed, active, calcareous, mesic

${ }^{3}$ Eutric Regosols (Clayic)

\section{${ }^{4}$ Medium Viqour}

Fig. 2 Soil layering description, soil type classification, and corresponding remotely-sensed vigor class of three different soil profiles excavated down to $1.40 \mathrm{~m}$ depth or until bedrock horizon in July 2019. Soil type classification according to ${ }^{1}$ Soil Map of Emilia-Romagna (Regione Emilia-Romagna, 2018), ${ }^{2}$ Keys of Soil Taxonomy (Soil Survey Staff, 2014), and ${ }^{3}$ World Reference Base (IUSS Working Group WRB, 2015). ${ }^{4}$ Correspondence with the NDVI map derived by satellite imagery at $5 \mathrm{~m}$ ground resolution. Within every soil profile, capital letters represent the master horizons, lowercase letters designate specific characteristics of master horizons, numbers indicate vertical subdivisions within a horizon (Soil Survey Staff, 2014). A Mineral horizons that have formed at the soil surface or below a layer dominated by organic soil materials (O horizon); B Mineral horizons that have formed below an A, E, or O horizon; BC) Transitional layer showing characteristics of both B and C horizons; C Mineral horizons that are little affected by pedogenic processes; (R) Strongly cemented to indurated bedrock; (g) Strong gleying; (k) Accumulation of secondary carbonates; (p) Tillage or other disturbance; (r) Weathered or soft bedrock; (ss) Presence of slickensides

(Ap1 and Ap2 at 10-30 and 0.30-0.65 m depth, respectively) were generally uniform in terms of total lime (16.6\% calculated as the average of the three layers), active lime (8.76\%), total N (1.63 g/kg), exchangeable K (468 ppm) and P (39.7 ppm) (Table 1). At $0.65 \mathrm{~m}$ depth, an alteration horizon (Bgkss) featuring vertic properties, secondary carbonates and strong gleying was described down to a depth of $1.15 \mathrm{~m}$. A Bgss horizon characterized the profile below a depth of $1.15 \mathrm{~m}$ showing similar conditions to the overlying layer. Moreover, in the sub-area of the vineyard associated with HV, soil profiling to a depth of $1.40 \mathrm{~m}$ did not reach the bedrock horizon $(\mathrm{R})$. Clay was the dominant soil texture class down the profile, with clay content frequently exceeding $50 \%$; silt

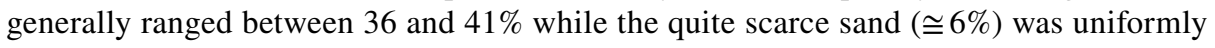
distributed down the profile. The organic matter content was similar among the Ap horizons $(\sim 2.4 \%)$ and decreased in the deeper Bgkss and Bgss layers (1.44 and 1.29\%, 


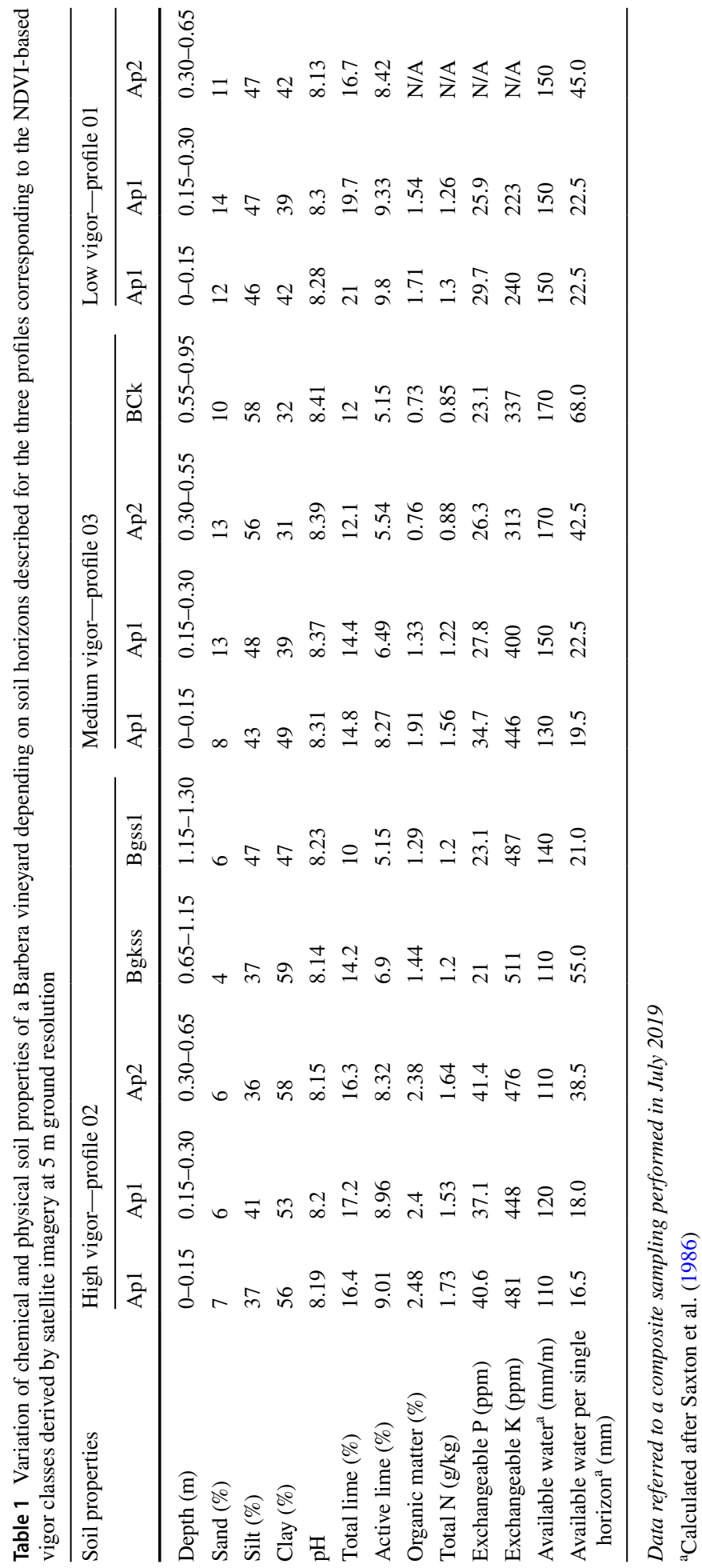


respectively). When compared to the regional Soil Map of Emilia-Romagna (2018), the profile matched with Vicobarone Soil (VCB1), clayey with 15-20\% slope grade (Fig. 2). Based on Keys to Soil taxonomy (Soil Survey Staff, 2014) and the World Reference Base (IUSS Working Group WRB, 2015) the soil was classified as Vertic Haplustepts fine, mixed, superactive, mesic, and Vertic Cambisols (Colluvic), respectively.

Soil profiling in MV showed moderately deep and well drained conditions. A paralithic contact $(\mathrm{Cr})$ limiting water infiltration was described at $0.95 \mathrm{~m}$ depth (Fig. 2 and Table S1). The top horizon Ap1 $(0-0.30 \mathrm{~m})$ was followed by Ap2 and BCk horizons at $0.30-0.55$ and $0.55-0.95 \mathrm{~m}$ depth intervals, respectively (Table 1). Soil texture in Ap1 varied depending on depth with higher clay (49\%) and lower sand (8\%) contents in the $0-0.15 \mathrm{~m}$ interval as compared to $0.15-0.30 \mathrm{~m}$ depth (39 and $13 \%$ for clay and sand, respectively). Interestingly, a progressive depletion in soil fertility was assessed from ground level to deeper layers as maximum vs minimum ranges for organic matter $(1.91-0.73 \%)$, total $\mathrm{N}(1.56-0.88 \mathrm{~g} / \mathrm{kg})$, exchangeable $\mathrm{K}(446-313 \mathrm{ppm})$ and $\mathrm{P}$ (34.7-23.1 ppm) were always associated with Ap1 and BCk horizons, respectively. When compared to the regional Soil Map of Emilia-Romagna (2018), the profile matched with Montalbo Soil (MNB1), clayey with 15-20\% slope grade (Fig. 2) and was classified as Typic Ustorthents fine, mixed, active, calcareous, mesic (Soil Survey Staff, 2014) and Eutric Regosols (Clayic) (IUSS Working Group WRB, 2015).

The soil profile in LV was moderately deep, well drained, clayey with a lithic contact at $0.65 \mathrm{~m}$ depth (R) limiting root growth and water availability (Fig. 2 and Table S1). Ap1 and Ap2 were described at $0-0.30 \mathrm{~m}$ and $0.30-0.65 \mathrm{~m}$ depth, respectively. Soil texture was mainly classified as silty-clay with sand, silt and clay particles mixed in the following proportion; $>10 \%, 46 \%$ and $\sim 40 \%$, respectively. The clay content in the first $0.15 \mathrm{~m}$ depth was lower than the other vigor zones, whilst total and active lime concentration had the highest rates of 21 and $9.8 \%$, respectively. Soil fertility, as based on organic matter and macro-nutrients, was moderate to low (Table 1). This soil was classified as Montalbo (MNB1) (Fig. 2).

Based on their agronomic properties, the differences in the three soil series mainly relied upon changes in texture, organic matter, macro-nutrients, soil depth and available water (Tables 1, S1). Absolute values for total available water (TAW) calculated after Saxton et al. (1986) were the lowest $(110-140 \mathrm{~mm} / \mathrm{m}$ of soil depth) for the soil horizons associated with the high vigor area (VCB, profile 2) due to a very high proportion of clay particles. However, soil depth was very high in HV (VCB) without any limiting horizons affecting root growth and deepening until $1.40 \mathrm{~m}$; the same property was classified as moderately high in MV and LV due to the occurrence of a paralithic layer $(\mathrm{Cr})$ and a lithic layer (R) at 0.95 and $0.65 \mathrm{~m}$ depth in MNB1 profiles, respectively. Combining these properties, (TAW) within the explorable soil depth was $149.0 \mathrm{~mm}, 152.5 \mathrm{~mm}$ and $90 \mathrm{~mm}$ for HV, MV and LV zones, respectively (Table 1).

Auger-based profiling allowed the classification of three of the nine sampling points as Vicobarone (VCB), while the remaining six points very closely matched with Montalbo (MNB1) (Regione Emilia-Romagna, 2018) (Table S2 and Fig. 1). When comparing auger-based soil classification with the NDVI map, samples associated with VCB (S1 and S3) perfectly matched with HV, while S4 fell in the MV even if located near the MV-HV interface. Inspections classified as MNB1 (S2, S5, S8 and S9) showed $100 \%$ overlapping with LV areas, while S7 fell in the MV. However, even if classified as MNB1, the vigor area related to S6 could not be clearly identified as it was located at the transition zone between MV and LV. 
When a principal component analysis (PCA) was carried out on 10 different soil and leaf parameters to assess the grouping of the three vigor levels, the F1 and F2 dimensions explained $85.27 \%$ of the variance in the data set and were chosen to plot the correlation circle and the observation bi-plot (Fig. 3). Looking at different reciprocal angles formed by the direction of the different PCA vectors, it was apparent that, for instance, soil depth (SD) held a strong positive relationship with total available water (TAW), clay fraction, $\mathrm{K}_{\text {soil }}$ and $\mathrm{N}_{\text {leaf }}$, whereas a negative relationship occurred with the sand fraction (Table $\mathrm{S} 3$ ). Soil organic matter (SOM) was linearly and positively correlated with clay fraction, $\mathrm{N}_{\text {soil }}$ and $\mathrm{P}_{\text {soil }}$, whereas the relationship was negative vs. the silt fraction. TAW was unrelated to either clay and silt fractions and negatively correlated with sandy particles. The observation bi-plot allowed a quite clear separation of the three vigor levels. HV was confined within the two right-hand quadrants and the parameters that especially contributed to such a precise placement were clay fraction, $\mathrm{N}_{\text {leaf }}$, $\mathrm{SD}$, TAW and $\mathrm{K}_{\text {soil }}$. Conversely, LV plotted into the bottom-left quadrant was associated with the sand fraction. MV showed a more erratic location as data were distributed within three quadrants and values tended to be distributed along the line that had silt and clay fractions at the two extremes (Fig. 3).

\section{Vegetative growth, yield and fruit composition}

Vegetative growth consistently differed among vigor classes with HV showing a higher capacity compared to MV and LV. Total pruning weight per vine linearly decreased with vigor, ranging between $984 \mathrm{~g}$ in $\mathrm{HV}$ to $605 \mathrm{~g}$ in LV. The same gradient was also respected for the main and lateral cane contributions although the reduction showed by LV vs HV values was higher for lateral canes $(-51 \%)$ than for main canes $(-35 \%)$ (Table 2). Vine capacity assessed as total leaf area (LA) was higher in $\mathrm{HV}\left(3.88 \mathrm{~m}^{2} / \mathrm{vine}\right)$ than in LV vines $\left(2.66 \mathrm{~m}^{2} /\right.$ vine $)$.

Yield per vine was positively correlated with increasing vigor, varying from $3.28 \mathrm{~kg}$ in $\mathrm{LV}$ to $6.6 \mathrm{~kg}$ in $\mathrm{HV}$, corresponding to a potential yield of 10.9 and $22.0 \mathrm{t} / \mathrm{ha}$, respectively (Table 2). Berry weight was lowest in LV (1.76 g) and highest in HV (2.25 g). Partitioning the significant vigor $\times$ year interactions for the parameters shown in Table 2 indicated that the nature of the interaction was additive, meaning that relative changes among vigor levels were maintained every year, yet the 2017 data showed larger differences (Fig. 4). The

Fig. 3 Principal component analysis (PCA) of 10 variables (axes F1 and F2: $85.27 \%$ total variance) for observation levels shown as a bi-pot graph. TAW total available water, SOM soil organic matter. Observations were: high vigor (HV); medium vigor (MV) and low vigor (LV)

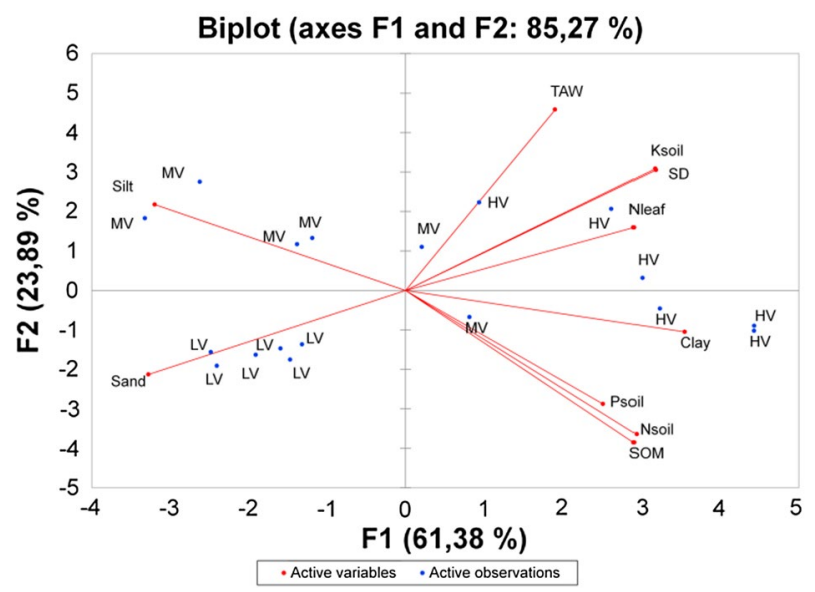




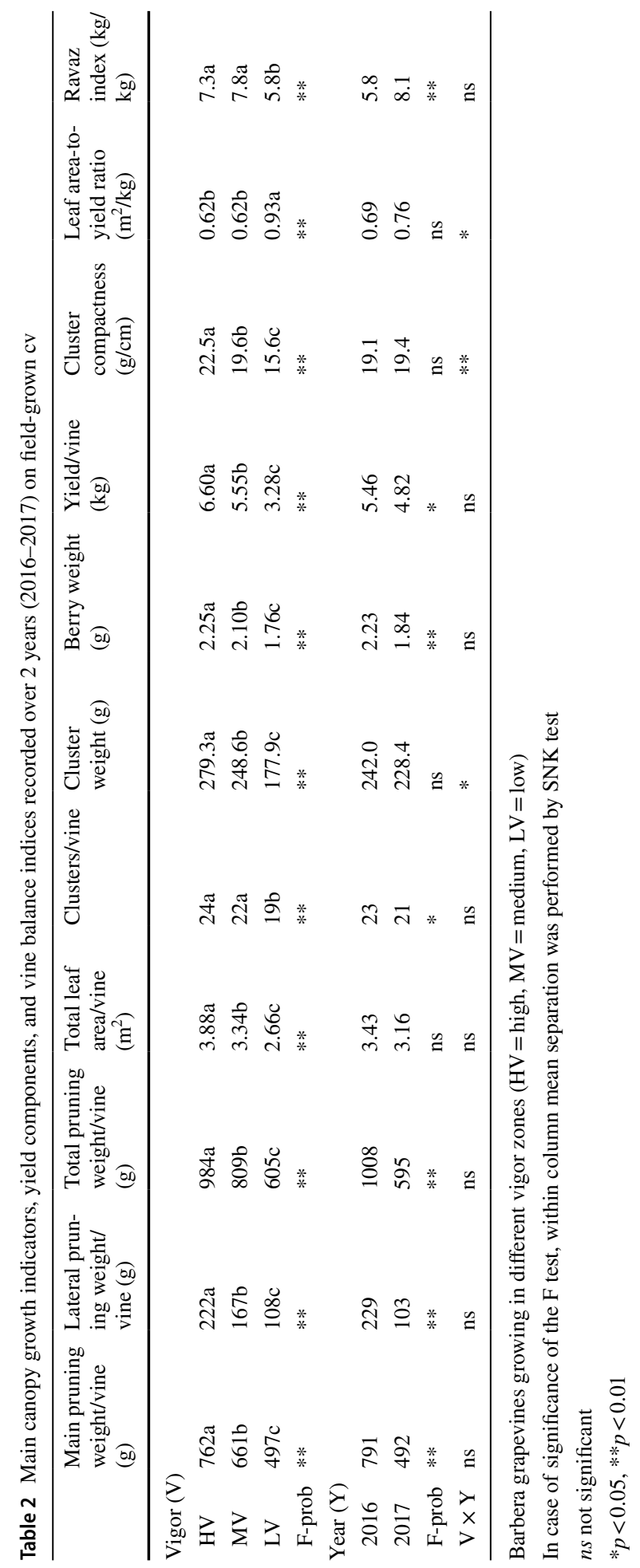


Fig. 4 Variation over years of cluster weight (A), cluster compactness (B) and leaf area-tofruit ratio $(\mathbf{C})$ of Vitis vinifera $\mathrm{L}$. cv Barbera grapevines depending on vigor levels (HV, MV, and LV). Vertical bar in each column represents the standard error (SE) $(\mathrm{n}=12)$
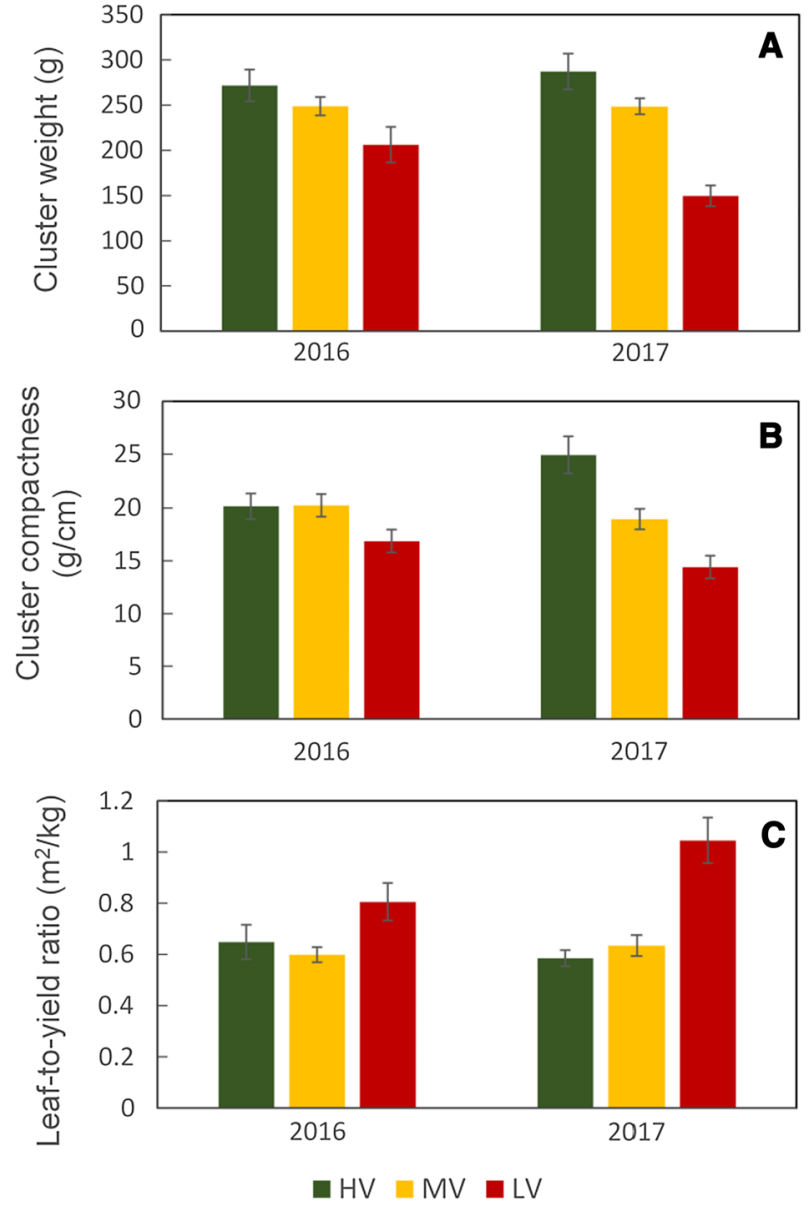

Ravaz index calculated as the yield-to-pruning weight ratio (Kliewer \& Dokoozlian, 2005) was consistently reduced in LV for data pooled over the two seasons (Table 2). Moreover, the lower the vigor, the higher the leaf-to-fruit ratio; the highest value of $1.05 \mathrm{~m}^{2} / \mathrm{kg}$ was registered in LV areas in 2017 whilst MV and HV did not exceed the $0.65 \mathrm{~m}^{2} / \mathrm{kg}$ threshold in either season (Fig. 4C).

Fruit ripening was largely enhanced in LV as compared to MV and HV (Table 3). At harvest, LV had higher TSS (25.5 Brix) and $\mathrm{pH}$ (3.24) and lower titratable acidity (7.76 g/l) than MV and HV. However, for TSS, the LV increase was much higher in 2017 (Fig. 5A), whereas malate in MV berries differed according to season: very similar to HV in 2016 and close to LV in the drier and warmer 2017 (Fig. 5B). In both the experimental years, anthocyanin and total phenolic concentration at harvest was higher in grapes from LV areas (Fig. 4C, D). Significant V $\times$ Y interaction for these parameters revealed that fruit composition did not differ between HV and MV in 2016 while significant differences among the three vigor zones were described during the second year (Fig. 5C, D).

Within year variation given as the coefficient of variation $(\mathrm{CV})$ of all measured parameters is summarised in Table S4. CV varied from the very stable 3.3 and $4.0 \%$ of must $\mathrm{pH}$ to the greatly varying $\mathrm{CV}$ of lateral pruning weight/vine (53.1 to 103.6\%). Except for malate, 
Table 3 Grape composition recorded over 2 years (2016-2017) on field grown cv

\begin{tabular}{|c|c|c|c|c|c|c|c|c|}
\hline & TSS $\left({ }^{\circ}\right.$ Brix $)$ & $\mathrm{pH}$ & $\mathrm{TA}(\mathrm{g} / \mathrm{l})$ & $\begin{array}{l}\text { Tartrate } \\
(\mathrm{g} / \mathrm{l})\end{array}$ & $\begin{array}{l}\text { Malate } \\
(\mathrm{g} / \mathrm{l})\end{array}$ & $\begin{array}{l}\text { Antho- } \\
\text { cyanins } \\
\text { (mg/g) }\end{array}$ & $\begin{array}{l}\text { Phenolics } \\
(\mathrm{mg} / \mathrm{g})\end{array}$ & $\mathrm{K}+(\mathrm{ppm})$ \\
\hline \multicolumn{9}{|c|}{ Vigor (V) } \\
\hline $\mathrm{HV}$ & $21.4 b$ & $3.18 \mathrm{ab}$ & $9.33 \mathrm{a}$ & $9.02 \mathrm{~b}$ & $3.32 \mathrm{a}$ & $0.886 b$ & $1.548 \mathrm{~b}$ & 2141 \\
\hline MV & $21.3 b$ & $3.16 \mathrm{~b}$ & $9.26 \mathrm{a}$ & $10.28 \mathrm{a}$ & $2.88 \mathrm{~b}$ & $1.031 \mathrm{~b}$ & $1.777 \mathrm{ab}$ & 1930 \\
\hline LV & $25.5 \mathrm{a}$ & $3.24 \mathrm{a}$ & $7.76 \mathrm{~b}$ & $10.20 \mathrm{a}$ & $2.08 \mathrm{~b}$ & $1.721 \mathrm{a}$ & $2.664 a$ & 2100 \\
\hline F-prob & $* *$ & $*$ & $* *$ & $* *$ & $* *$ & $* *$ & $* *$ & ns \\
\hline \multicolumn{9}{|l|}{ Year (Y) } \\
\hline 2016 & 22.9 & 3.25 & 9.01 & 10.04 & 2.88 & 1.338 & 1.959 & 1899 \\
\hline 2017 & 22.6 & 3.15 & 8.55 & 9.63 & 2.64 & 1.094 & 2.041 & 2214 \\
\hline F-prob & ns & $* *$ & ns & ns & ns & $* *$ & ns & $* *$ \\
\hline $\mathrm{V} \times \mathrm{Y}$ & $*$ & ns & ns & ns & $* *$ & $*$ & $*$ & $*$ \\
\hline
\end{tabular}

Barbera grapevines growing in different vigor zones ( $\mathrm{HV}=$ high, $\mathrm{MV}=$ medium, $\mathrm{LV}=\mathrm{low}$ )

In case of significance of the F test, within column mean separation was performed by SNK test $n s$ not significant

$* p<0.05, * * p<0.01$,
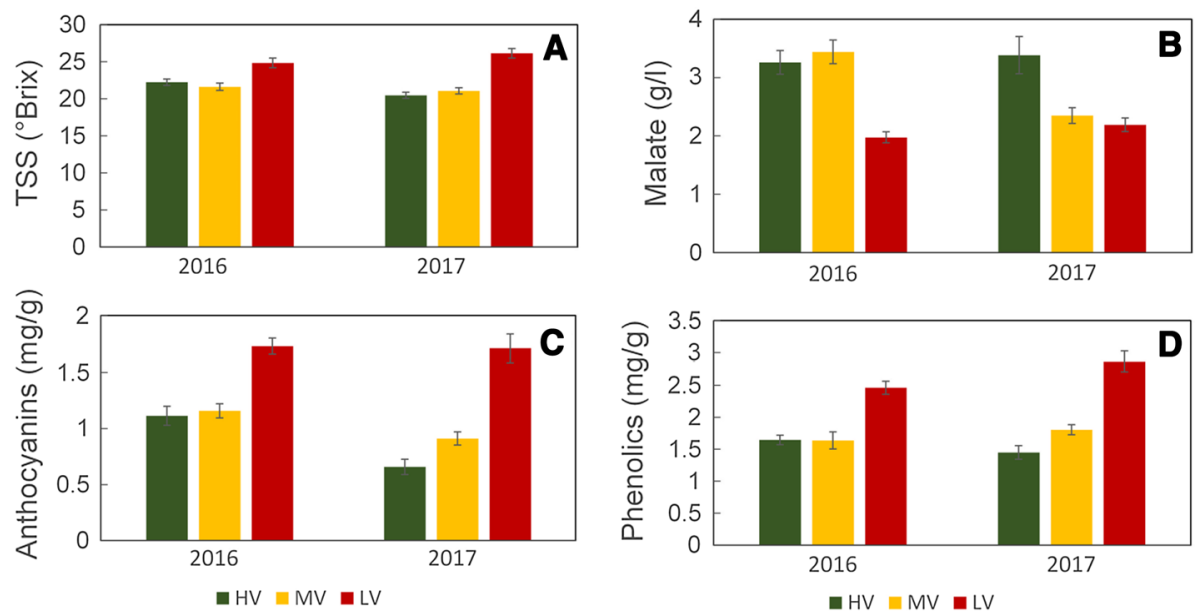

Fig. 5 Variation over years of total soluble solids (A), malic acid (B), total anthocyanins $(\mathbf{C})$ and total phenolics (D) concentrations in grapes of Vitis vinifera L. cv Barbera grapevines depending on vigor levels (HV, MV and LV). Vertical bars of each column represent standard error (SE) $(n=12)$ 
technological ripening variables (i.e. TSS, TA, tartrate) showed a lower CV both within and across seasons than phenolic ripening parameters and yield components.

\section{Nutritional status, dry matter and nutrients accumulation and partitioning}

Leaf blade concentrations of macro and trace elements assessed at veraison in both experimental years are reported in Table 4. Vigor only affected leaf N, Ca, Na and Fe concentration. HV resulted in higher N leaf concentration (2.08\% DM) compared to MV $(1.90 \%$ $\mathrm{DM})$ and LV (1.85\% DM). Conversely, the lowest vigor had the highest $\mathrm{Ca}$ and Fe levels at 3.04\% DM and 100 ppm, respectively in LV zones. Differences in mineral status depending on vigor were quite consistent over seasons as the vigor $\mathrm{x}$ year interactions were not significant for almost all the nutrients.

Annual dry matter accumulation increased with vigor (Table 5). In 2016 dry weight was lowest in LV (5.5 t/ha) and peaked at $9.2 \mathrm{t} / \mathrm{ha}$ in HV; similarly, in 2017, annual biomass linearly increased from $4.4 \mathrm{t} / \mathrm{ha}(\mathrm{LV})$ to $7.5 \mathrm{t} / \mathrm{ha}(\mathrm{HV})$. Clusters were the most important C-sink accounting for $59.8 \%$ and $67.2 \%$ of total dry matter in 2016 and 2017 , respectively. The second most important carbon sink were the canes, accounting for $19.9 \%$ and $14.6 \%$ total dry matter in 2016 and 2017, respectively. The fraction of dry biomass removed with trimming largely increased according to vigor in both years (Table 5).

Nutrients content ( $\mathrm{kg}$ or $\mathrm{g} / \mathrm{ha}$ ) determined in different vine organs for each vigor level were extremely consistent, showing a decreasing trend from HV to LV; out of 120 withinvigor combinations (12 nutrients $\times$ two seasons $\times$ five vine organs), 65 showed a significant difference $(\mathrm{p}<0.05)$ between $\mathrm{HV}$ and LV. The array of differences did not group within any specific season. When the same data were given on a concentration basis (\% or ppm over DM), out of the same 120 possible within-vigor combinations, only 15 showed a significant statistical difference (Table 6).

\section{Discussion}

The first objective of this work was to combine detailed soil description and vine performance ground-truthing to clarify the main sources and the extent of observed intra-vineyard variability. Albeit limited to two seasons and to a small 1.2 ha vineyard plot, differential behaviour of $\mathrm{HV}$ and $\mathrm{LV}$ zones was consistent and independent from season variability, even though 2017 was hotter and drier than 2016 (Fig. S1). This observation was supported by the presence of very few significant year $\times$ vigor interactions for any of the measured parameters. Even when such interactions were significant (Figs. 4 and 5), they were always categorised as "spreading" rather than "cross-over" interactions, meaning that, taking for instance cluster weight, LV always had lower cluster weight compared to HV but to a higher extent in the drier 2017 season.

A fairly constant spatial intra-vineyard variability was described over the 2 years. Moreover inputs and cultural practices were uniformly applied over the whole block, as well as the same plant material being used when establishing the vineyard in 2011. As a consequence, it is quite intuitive, as confirmed by a number of studies (Arno et al., 2012; Kotsaki et al., 2019; Tardaguila et al., 2011; Trought et al., 2008), that variation in vine performance, grape composition and the resulting wines is attributable to environmental variation (soil, topography etc.) underlying the vineyard. This is a quite crucial issue since exploitation of observed spatial variability through either targeted vineyard management or 


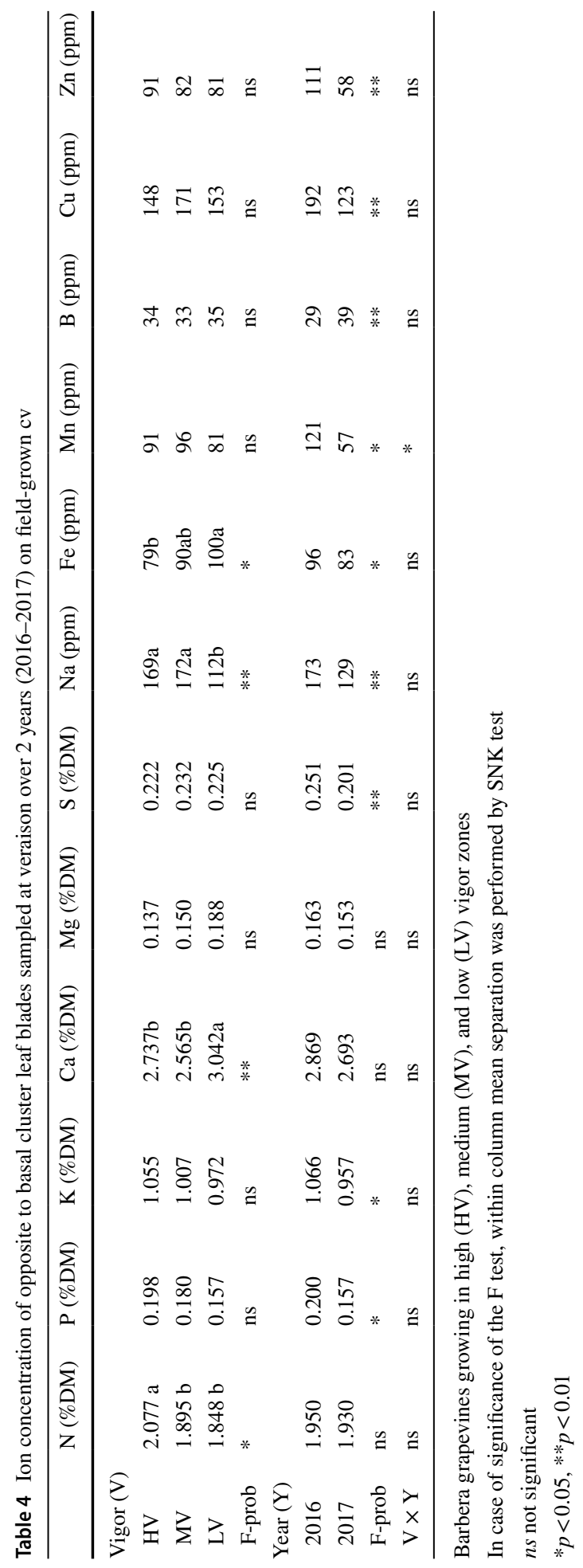




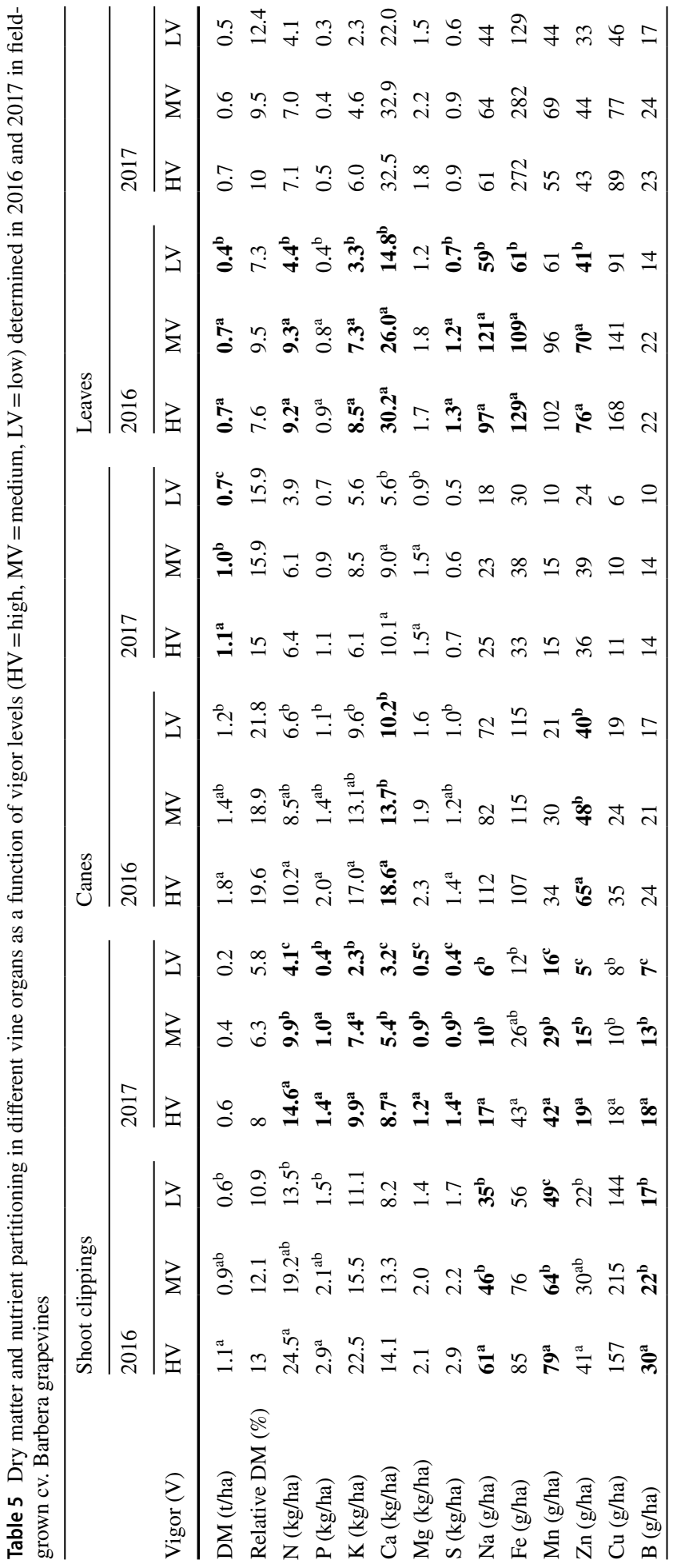




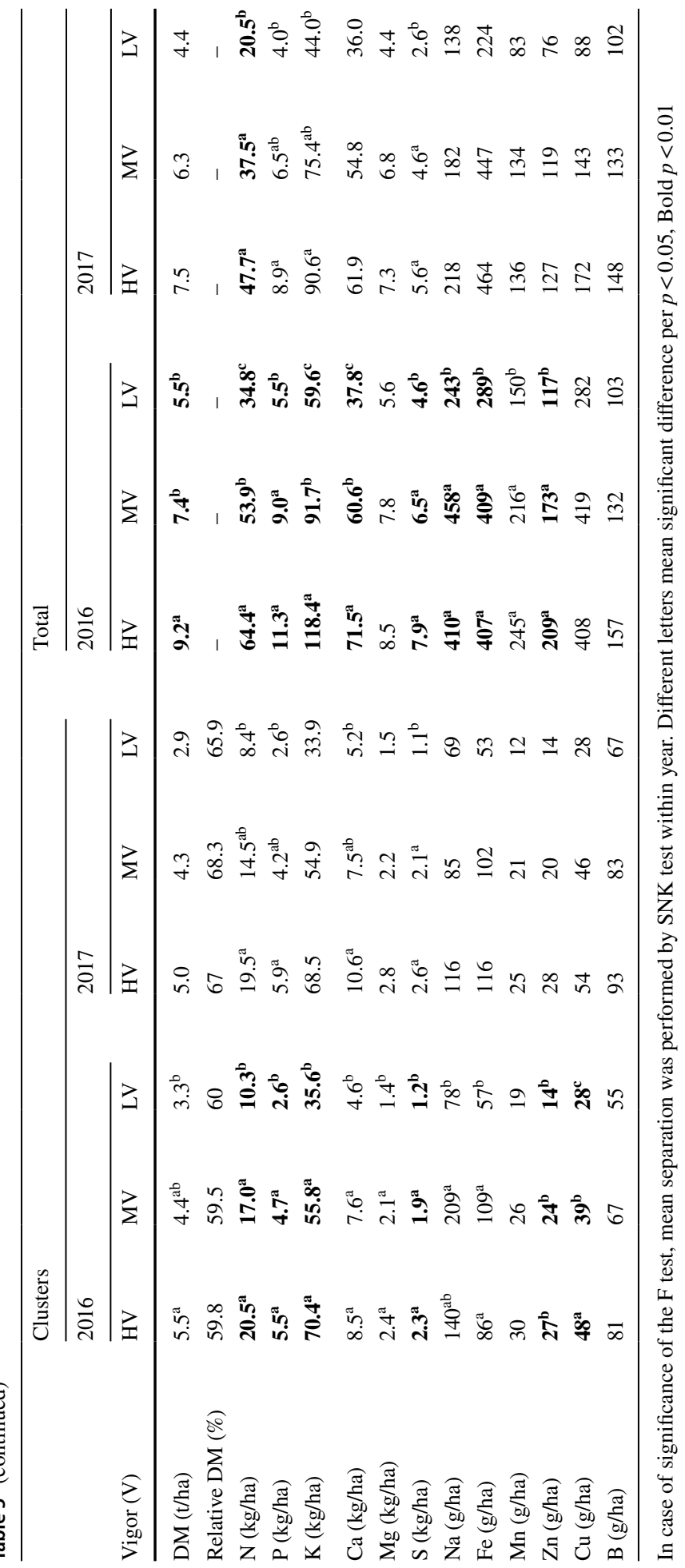




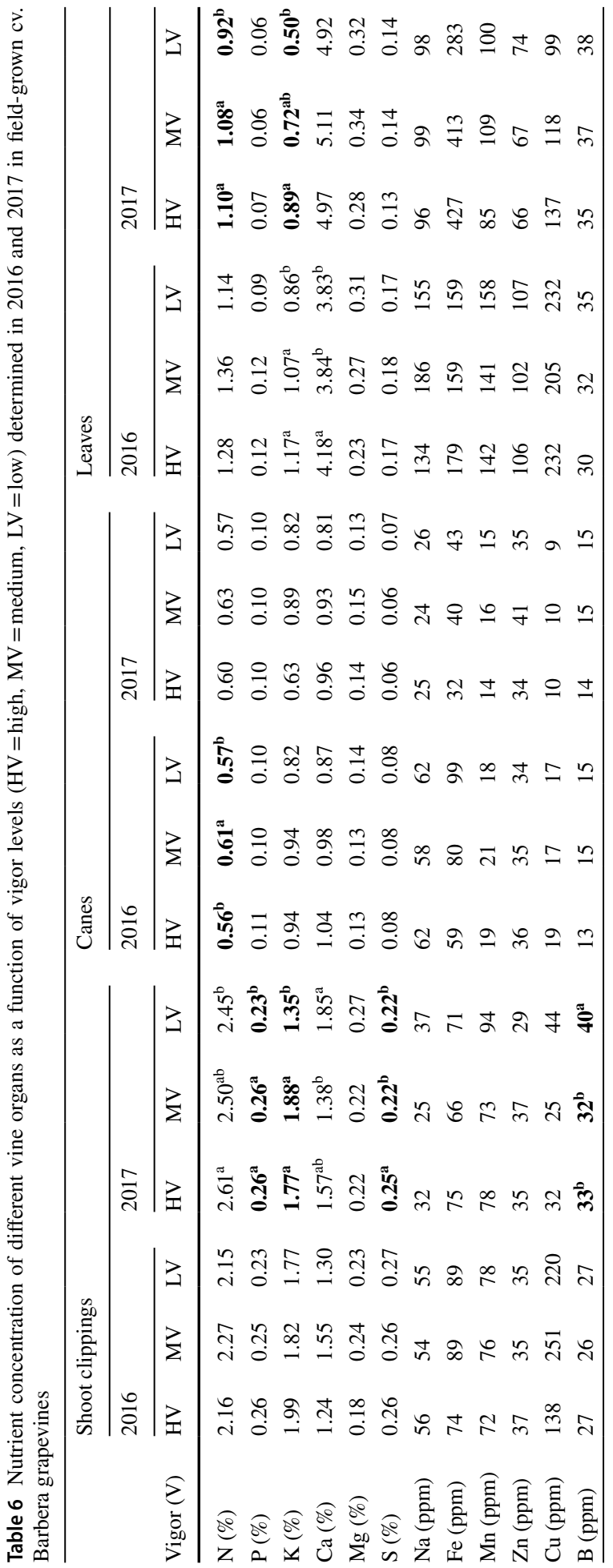




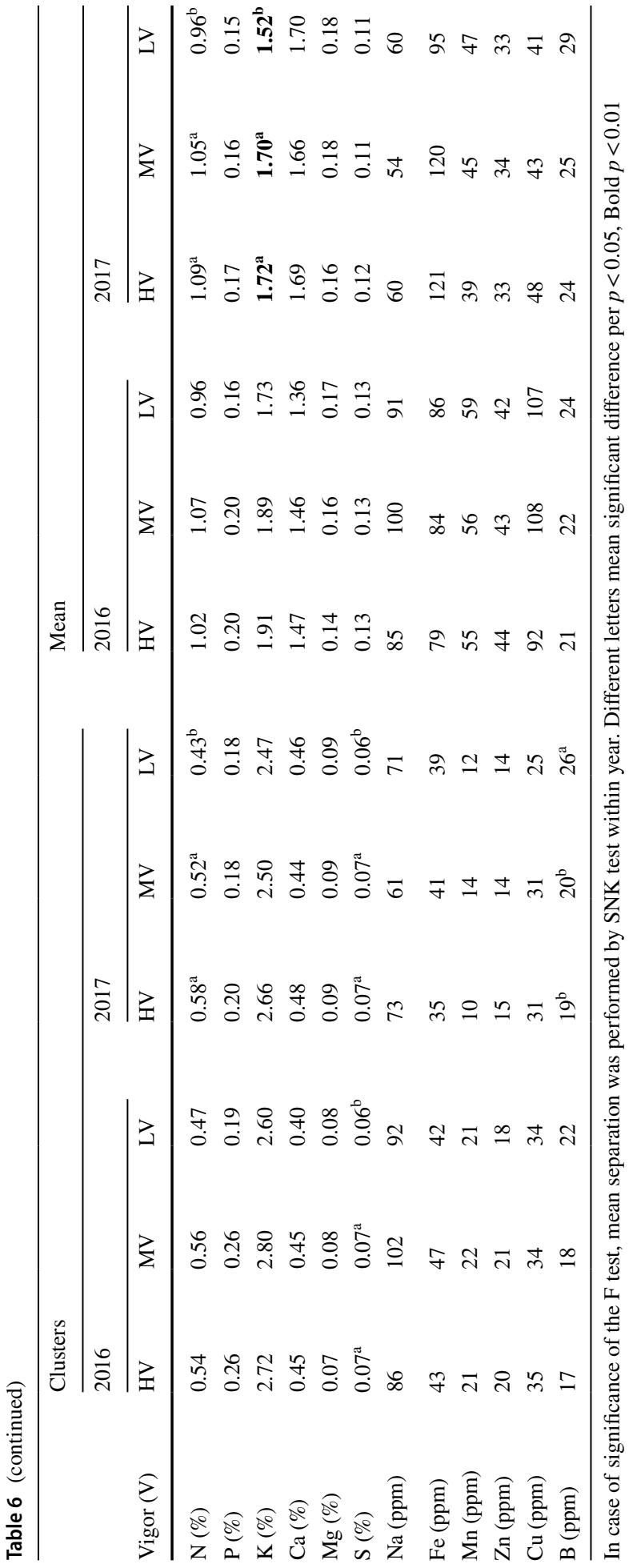


application of a variable rate strategy (Gatti et al., 2020; Maes \& Steppe, 2019), including rootstock differentiation at planting, will be easier if the spatial variability is strong and constant over time. However, matching vigor mapping with soil features is time consuming and costly since soil properties, fertility (soil- and plant-based) and a series of vine performance parameters should be concurrently evaluated. As a result, studies have undergone such an endeavour. The most comprehensive survey carried out on the matter has been the 3-year study of Tardaguila et al. (2011) on Tempranillo, who tried to correlate soil features with differential vegetative growth and yield detected within the same parcel. Albeit the zone delineation was not driven by remote sensing in their case, it was demonstrated that soil units with differing absolute values of soil depth, soil organic matter (SOM), clay fraction and cation exchange capacity (CEC) were closely and linearly correlated with several vine vigor and yield parameters. The PCA analysis carried out here also confirmed that soil depth (SD), clay fraction and SOM played a role in characterizing the high vigor zones. In this study, other important factors were also identified, namely $\mathrm{N}_{\text {leaf }}, \mathrm{K}_{\text {soil }}$ and total available water (TAW). It was noted that small variations in the sand fraction and consequent changes in soil properties related to it might be sufficient to shift sites from the HV area to the LV area (Fig. 3). This is in full accordance with the emphasis that Trought et al. (2008) gave to an increasing fraction of gravelly soil that advanced phenology and markedly improved ripening of Sauvignon blanc vines grown in Marlborough, New Zealand. In other extensive studies carried out on the inter-annual spatial variability of Riesling grown in Ontario vineyards (Kotsaki et al., 2019; Willwerth \& Reynolds, 2020a, b), the most consistent and stable soil feature that impacted vine performance, yield components and grape quality was again texture; interestingly though, spatial variability assessment of different parameters showed that the most stable of all was midday leaf water potential $\left(\psi_{1}\right)$ that was constantly less negative in high vigor plots. This accords quite well with the findings as chances to maintain a less negative $\psi_{1}$ at high evaporative demand during the day are related to higher available water in the root zone (Gatti et al., 2020) and roots that can absorb water from deeper and wetter soil horizons. In this study, correlation matrix of PCA analysis (Table $\mathrm{S} 3$ ) showed that $\mathrm{N}_{\text {soil }}$ and $\mathrm{N}_{\text {leaf }}$ were not significantly correlated $(\mathrm{r}=0.394$, $\mathrm{ns}$ ); however, looking at the specific position in the correlation circle for these two parameters, it appears that the parameter more relevant for determining $\mathrm{HV}$ placement was $\mathrm{N}_{\text {leaf }}$. This was quite interesting as it indicated that $\mathrm{N}_{\text {leaf }}$ could act as a diagnostic tool to identify vigor levels. Recent work by Squeri et al. (2019) has ascertained that several broadband VIS-NIR indices can be profitably used for non-destructive estimates of $\mathrm{N}_{\text {leaf }}$ concentration therefore making the procedure fast and effective.

In this study, a consistent differentiation between HV and LV performance held for all the measured parameters with the exception of $\mathrm{K}^{+}$concentration in berries at harvest. This outcome was somewhat different from what other studies have indicated about the ability of individual parameters to respond to intra-vineyard spatial variability. For instance, work conducted for 3 years on cv Tempranillo (Baluja et al., 2013; Tardaguila et al., 2011) concluded that inter-annual stability was only high for TSS and TA, whereas total phenols and anthocyanins showed a more erratic spatial pattern that proved to be highly sensitive to the inter-relationships between soil, weather and the vine system. A similar conclusion was reached by Arno et al. (2012), Bramley and Lamb (2003), and Verdugo-Vásquez et al. (2018), who showed that inter-annual spatial yield patterns are definitely more consistent than those for grape quality patterns. In terms of intra-annual variability, a study run on Cabernet Sauvignon and Ruby Cabernet (Bramley \& Hamilton, 2004) confirmed that the "spread", calculated as the difference between maximum and minimum values then given as a fraction of the median values was much higher for phenolics $(117 \%)$ than for TSS 
(20\%). In this work, within-season variation of each recorded parameter varied greatly: not surprisingly, the parameter showing the highest seasonal variation (CV values ranging between 53.1 and $105.6 \%$ in 2016 and 2017, respectively) was lateral winter pruning weight per vine that, quite typically, is supposed to be one of the most reliable indices to express "vigor" (Smart, 1985). In contrast, the most stable parameter was must $\mathrm{pH}$ (CV varying from 3.3 to $4.0 \%$ ) (Table S4). In agreement with some of the cited works, TSS variation was definitely lower (CV ranging between 11 and $14.4 \%$ in the two seasons) than that calculated for total anthocyanins $(30.3<\mathrm{CV}<52.4 \%)$ (Table S4). Ample withinyear variation of these parameters is not surprising at all. Taking example of TSS vs total anthocyanins behaviour, while both are quite sensitive to crop load, it is well understood that TSS primarily react to whole-canopy photosynthesis (Salazar-Parra et al. 2018; Smith et al., 2019), whereas colour accumulation is more heavily impacted by local micro-climate conditions and cultural practices affecting light distribution in the fruiting area and, most importantly, cluster temperature (Haselgrove et al., 2000; Poni et al., 2018). Nonetheless, inter-annual spatial variability in this study was definitely minor regardless of any involved growth, yield or fruit quality parameters.

A survey of papers that have dealt with soil features and vine performance at withinfield scale shows that several methodologies have been used for assessing spatial variability. Visual assessment of the geo-morphological features of the terrain was used by Tardaguila et al. (2011), georeferenced ground-based measurements and photographic methods were considered, respectively, by Willwerth and Reynolds (2020a, b) and Baluja et al. (2013) whilst electromagnetic induction was adopted by Priori et al. (2019). Moreover, yield maps from a self-propelled grape harvester equipped with load-cell based yield monitor device was the method chosen by Arno et al. (2012) while Gatti et al. (2016) mapped the variability of canopy vigor by using a proximal sensing system. Having used, as Bramley et al. (2011) did, a remote sensing approach, this might influence the representativeness of different vigor levels from ground-truthing and, in turn, the precision in estimating the stability of inter-annual spatial variability. Moreover, if yield is solely taken as a descriptor of spatial variability, the same "high" yield might turn out to enhance color accumulation in a season conducive to excessive vigor, or result in the opposite response if the season is dry and vine weakening becomes excessive. Working in the high-yielding Lambrusco grapevine district, Squeri et al. (2021b) recently discussed the important role of groundtruthing of remotely sensed vigour maps for developing an adequate management strategy for neighbouring Vitis vinifera L. cvs. Lambrusco Salamino and Ancellotta vineyards. They concluded that the labelling of vigor areas without site-specific ground-truthing can lead to quite deceptive information. More specifically, their paper showed that there is a varietal susceptibility to intra-vineyard variability (i.e. Ancellotta is much more reactive than Lambrusco Salamino) and, under the high vigor conditions where these cultivars are grown (Central Po Valley, in Italy), a golden rule to be respected to increase either yield or grape quality is that winter pruning weight should never exceed $1 \mathrm{~kg}$ per metre of row. A take home message from this study is that to counteract the confounding effect that a nonquantified vigor level might have, ground truthing of spatial variability assessment should always encompass both vegetative growth and yield, with optimum to be represented by a source-to-sink mapping (Taylor et al., 2019), using either leaf area-to-yield ratio or Ravaz index. Alternatively, step forwards could be made with a more recurrent use of fast indices allowing producers to estimate the temporal stability of intra-season spatial variability in permanent crops (Taylor et al., 2019).

The second hypothesis made in this study was that spatial variability in vine vigor and yield could also affect partitioning patterns of dry matter (DM) and nutrients into different 
vine organs. There is a lack of information in the literature about this aspect and these data represent a first attempt to determine if and how intra-vineyard spatial variability assessed through remote sensing will influence these parameters. It is a shared opinion (Flore \& Lakso, 1989; Vivin et al., 2002; Williams et al., 1994) that carbon (C) allocation is primarily ruled by the sink strength of plant organs, which is defined by the potential growth rate, plus carbon losses through growth and maintenance respiration processes, and carbon demand related to active reserve storage. Moreover, different authors have reported that soil physical and hydrological properties may influence root development and consequently water and mineral nutrition of the grapevine (Brillante et al., 2016; Morlat \& Bodin, 2006). Spatial variability of the soil properties within this experimental vineyard identified the co-existence of VCB and MNB1 soil types and their matching with HV and LV zones of a NDVI map, respectively (Table S2). Variations in soil might result in a different rooting pattern leading to deeper root development in VCB compared to MNB1 that was characterized by stronger physical and nutritional limitations (Tables 1, S1 and Fig. 3). This theory is supported by Morlat and Jaquet (1993) working on vineyards in the Loire Valley who demonstrated minimal root development in Cabernet franc/SO4 vines grown on low-SOM sandy soil (Senonian) compared to vines grown on a micaceous chalk of middle Turonian origin. In addition, due to the strict relationship existing between above vs below ground biomass described for different varieties and growing conditions (Miranda et al., 2017), the different capacity of the root systems depending on the soil type was confirmed by the lower total dry matter accumulated in LV compared to HV vines. According to previous works (Flore \& Lakso, 1989; Miranda et al., 2017; Morlat \& Jaquet, 1993; Vivin et al., 2002; Williams et al., 1994), it was not surprising that higher vine capacity displayed in HV vines led, each season, to the highest total annual current dry matter biomass, with LV vines scoring the lowest (Table 5). However, it is worth noting that, within each season, the fraction of DM stored into the main vine sink (clusters) was very constant across vigor levels at approximately 60\% in 2016 and $67 \%$ in 2017 . This result is especially interesting for the LV vines where, according to Miller and Howell (1998), the lower crop level (3.64 kg/vine vs $6.81 \mathrm{~kg} / \mathrm{vine}$ of HV in 2016 and $2.92 \mathrm{~kg} / \mathrm{vine}$ vs $6.39 \mathrm{~kg} / \mathrm{vine}$ of $\mathrm{HV}$ in 2017) should have led to a reduction of the carbohydrate partitioning to the cluster sink to the benefits of competing vegetative sinks. This was not the case for two main reasons: LV also encompassed a reduction in competitive vegetative sinks as clearly confirmed by the curtailed lateral pruning weight that has likely counteracted the decreased cluster sink strength in this vigor level. Following this, it should be also noted that the overall sourcesink balance expressed as total leaf area-to- yield ratio was actually improved in LV, representing an additional reason for $\mathrm{C}$ allocation compensation towards the clusters. Finally, data reported in Table 2 confirm that, within the vigor levels, main actor driving DM partitioning was extent of vegetative growth. Indeed, the main effect for the year factor shows that, in 2017, despite a significantly lower yield/vine across vigor levels (- $12 \%$ as compared to 2016), the fraction of DM directed to clusters increased, on average by $7 \%$, indicating that the drastically reduced vegetative vigor of 2017 ( $-41 \%$ in total pruning weight vs 2016) over-compensated for the more limited cluster sink strength.

When it comes to nutrients, the effects were very similar although each nutrient had different mobility rates across the soil-root-plant continuum (Marschner, 1995). Overall, the content of main nutrients recovered in different vine organs and given as total per surface basis ( $\mathrm{kg} / \mathrm{ha}$ ) showed a decreasing trend from HV to LV (Table 5). Once again, within seasons and across vigor levels, no significant variations were found. For example, fractional partitioning of $\mathrm{N}$ and $\mathrm{K}$ to clusters ranged from $30-31 \%$ and $59-61 \%$ in 2016 and $39-41 \%$ and $73-76 \%$ in 2017. Most of the significant differences vanished 
when nutrients were given as a concentration over total DM (Table 6), confirming the hypothesis above for total dry matter.

\section{Conclusions}

A 2 year study conducted to assess and calibrate intra-vineyard spatial variability in a Barbera vineyard block showed that, between vigor zones, differences in vine and berry parameters were strong and stable across two quite different seasons. These differences were very much related to soil and canopy factors that allowed the HV vine behaviour to be clearly separated from MV and LV vines. As soil variability was the main driver of these differences, expectations are that the described spatial variability will be quite stable over years, hence paving the way to differential zone management within the same vineyard aimed, for example, at getting different wine types that can be more profitably marketed. When dry matter and nutrient partitioning into different vine organs for each vigor level were evaluated either as absolute values (i.e. unit weight/ ha) or on a relative basis (fractions of DM), it was clear that absolute values linearly changed along the vigor gradient, whereas concentrations were mostly unaffected by vigor profiles. Again, this is a positive feature if practical exploitation of the technique is pursued since, regardless of recorded vigor levels, sink strength is not significantly affected and nutrient allocation is unlikely to be altered across the vineyard. As a matter of fact, implementation of variable rate fertilization strategies through prescription map should be driven by expected DM production.

Supplementary Information The online version contains supplementary material available at https://doi. org/10.1007/s11119-021-09831-w.

Acknowledgements The authors want to thank Paolo Malvicini Estate for hosting the trial, Studio di Ingegneria Terradat for providing the vigor map, and Alice Richards for English Language Editing.

Author Contributions MG, SP, and CaS conceived and planned the study. AG, CeS and ID carried out the experiment and analysed the data. ADM and CaS provided the expertise for soil characterization. MG and SP wrote the first draft of the manuscript. All authors reviewed and edited the manuscript.

Funding Open access funding provided by Università Cattolica del Sacro Cuore within the CRUI-CARE Agreement. Research carried out within the Nutrivigna (Grant n. J32J16000090007) and VinCapTer (id. 5015583) projects funded by the Emilia-Romagna Region under the POR-FESR program (2014-2020) and the Rural Development Program (2014-2020), respectively.

Data availability The datasets generated during and/or analysed during the current study are available from the corresponding author on reasonable request.

\section{Declarations}

Conflict of interest The authors have no relevant financial or non-financial interests to disclose.

Ethical approval The authors comply with the Journal's Ethics guidelines confirming to respect third parties rights such as copyright and/or moral rights.

Informed consent All authors agreed with the content and gave explicit consent to submit. 
Open Access This article is licensed under a Creative Commons Attribution 4.0 International License, which permits use, sharing, adaptation, distribution and reproduction in any medium or format, as long as you give appropriate credit to the original author(s) and the source, provide a link to the Creative Commons licence, and indicate if changes were made. The images or other third party material in this article are included in the article's Creative Commons licence, unless indicated otherwise in a credit line to the material. If material is not included in the article's Creative Commons licence and your intended use is not permitted by statutory regulation or exceeds the permitted use, you will need to obtain permission directly from the copyright holder. To view a copy of this licence, visit http://creativecommons.org/licenses/by/4.0/.

\section{References}

Arnó, J., Rosell, J. R., Blanco, R., Ramos, M. C., \& Martínez-Casasnovas, J. A. (2012). Spatial variability in grape yield and quality influenced by soil and crop nutrition characteristics. Precision Agriculture, 13(3), 393-410. https://doi.org/10.1007/s11119-011-9254-1

Baluja, J., Tardaguila, J., Ayestaran, B., \& Diago, M. P. (2013). Spatial variability of grape composition in a Tempranillo (Vitis vinifera L.) vineyard over a 3-year survey. Precision Agriculture, 14(1), 40-58. https://doi.org/10.1007/s11119-012-9282-5

Bavaresco, L., Gatti, M., \& Fregoni, M. (2010). Nutritional deficiencies. In S. Delrot, H. Medrano, E. Or, L. Bavaresco, \& S. Grando (Eds.), Methodologies and results in grapevine research (pp. 165191). Springer. https://doi.org/10.1007/978-90-481-9283-0_12

Bonilla, I., Martinez de Toda, F., \& Martínez-Casasnovas, J. A. (2015). Vine vigor, yield and grape quality assessment by airborne remote sensing over three years: Analysis of unexpected relationships in cv. Tempranillo. Spanish Journal of Agricultural Research, 13(2), 1-8. https://doi.org/10. 5424/sjar/2015132-7809

Bramley, R. G. V., \& Hamilton, R. P. (2004). Understanding variability in winegrape production system. 1. Within vineyard variation in yield over several vintage. Australian Journal of Grape and Wine Research, 10(1), 32-45. https://doi.org/10.1111/j.1755-0238.2004.tb00006.x

Bramley, R. G. V., \& Lamb, D. W. (2003). Making sense of vineyard variability in Australia. In Proceedings IX Congreso Latinoamericano de Viticultura y Enología (pp. 35-54). Centro de Agricultura de Precisión, Pontificia Universidad Católica de Chile, Faculdad de Agronomía e Ingenería Forestal

Bramley, R. G. V., Proffitt, A. P. B., Hinze, C. J., Pearse, B., \& Hamilton, R. P. (2005). Generating benefits from precision viticulture through selective harvesting. In J. V. Stafford (Ed.), Proceedings of the 5th European Conference on Precision Agriculture (pp. 891-898). Wageningen Academic Publishers.

Bramley, R. G. V., Trought, M. C. T., \& Praat, J. P. (2011). Vineyard variability in Marlborough, New Zealand: Characterising variation in vineyard performance and options for the implementation of Precision Viticulture. Australian Journal of Grape and Wine Research, 17(1), 72-78. https://doi.org/10. 1111/j.1755-0238.2010.00119.x

Brillante, L., Bois, B., Lévêque, J., \& Mathieu, O. (2016). Variations in soil-water use by grapevine according to plant water status and soil physical-chemical characteristics-A 3D spatio-temporal analysis. European Journal of Agronomy, 77, 122-135. https://doi.org/10.1016/j.eja.2016.04.004

Dai, Z. W., Ollatm, N., Gomès, E., Decrooq, S., Tandonnet, J. P., Bordenave, L., et al. (2011). Ecophysiological, genetic, and molecular causes of variation in grape berry weight and composition: A review. American Journal of Enology and Viticulture, 62(4), 413-425. https://doi.org/10.5344/ajev.2011. 10116

Deloire, A., Vaudour, E., Carey, V. A., Bonnardot, V., \& van Leeuwen, C. (2005). Grapevine responses to terroir: a global approach. OENO One, 39(4), 149-162. https://doi.org/10.20870/oeno-one.2005.39.4. 888

Fiorillo, E., Crisci, A., De Filippis, T., Di Gennaro, S. F., Di Blasi, S., Matese, A., et al. (2012). Airborne high-resolution images for grape classification: Changes in correlation between technological and late maturity in a Sangiovese vineyard in Central Italy. Australian Journal of Grape and Wine Research, 18(1), 80-90. https://doi.org/10.1111/j.1755-0238.2011.00174.x

Flore, J. M., \& Lakso, A. N. (1989). Environmental and physiological regulation of photosynthesis in fruit crops. Horticultural Reviews, 11, 111-157.

Gatti, M., Dosso, P., Maurino, M., Merli, M. C., Bernizzoni, F., Pirez, F. J., et al. (2016). MECS-VINE®: A new proximal sensor for segmented mapping of vigor and yield parameters on vineyard rows. Sensors, 16(12), 2009. https://doi.org/10.3390/s16122009 
Gatti, M., Garavani, A., Vercesi, A., \& Poni, S. (2017). Ground-truthing of remotely sensed within-field variability in a cv. Barbera plot for improving vineyard management. Australian Journal of Grape and Wine Research, 23(3), 399-408. https://doi.org/10.1111/ajgw.12286

Gatti, M., Schippa, M., Garavani, A., Squeri, C., Frioni, T., Dosso, P., et al. (2020). High potential of variable rate fertilization combined with a controlled released nitrogen form at affecting $\mathrm{cv}$. Barbera vines behavior. European Journal of Agronomy, 112, 125949. https://doi.org/10.1016/j.eja.2019.125949

Gatti, M., Squeri, C., Garavani, A., Vercesi, A., Dosso, P., Diti, I., et al. (2018). Effects of variable rate nitrogen application on cv. Barbera performance: vegetative growth and leaf nutritional status. American Journal of Enology and Viticulture, 69(3), 196-209. https://doi.org/10.5344/ajev.2018.17084

Hall, A., Lamb, D. W., Holzapfel, B. P., \& Louis, J. P. (2011). Within-season temporal variation in correlations between vineyard canopy and winegrape composition and yield. Precision Agriculture, 12(1), 103-117. https://doi.org/10.1007/s11119-010-9159-4

Haselgrove, L., Botting, D., Van Heeswijck, R., Høj, P. B., Dry, P. R., Ford, C., et al. (2000). Canopy microclimate and berry composition: The effect of bunch exposure on the phenolic composition of Vitis vinifera L. cv Shiraz grape berries. Australian Journal of Grape and Wine Research, 6(2), 141-149. https://doi.org/10.1111/j.1755-0238.2000.tb00173.x

Iandolino, A. B., \& Williams, L. E. (2014). Recovery of $15 \mathrm{~N}$ labeled fertilizer by Vitis vinifera 1. cv. Cabernet Sauvignon: Effects of $\mathrm{N}$ fertilizer rates and applied water amounts. American Journal of Enology and Viticulture, 65(2), 189-196.

Iland, P. G. (1988). Leaf removal effects on fruit composition. In Smart, R., Thornton, R., Young, S.R.J. (Eds.), Proceedings of the Second International Symposium for Cool Climate Viticulture and Oenology (pp. 137-138). New Zealand Society for Viticulture and Oenology.

IUSS Working Group WRB. (2015). World Reference Base for Soil Resources 2014, update 2015. International soil classification system for naming soils and creating legends for soil maps. World Soil Resources Reports No. 106. FAO, Rome.

Johnson, L. F. (2003). Temporal stability of an NDVI-LAI relationship in a Napa Valley vineyard. Australian Journal of Grape and Wine Research, 9(2), 96-101. https://doi.org/10.1111/j.1755-0238.2003. tb00258.x

Kazmierski, M., Glemas, P., Rousseau, J., \& Tisseyre, B. (2011). Temporal stability of with-in-field patterns of NDVI in non irrigated mediterranean vineyards. Journal International Des Sciences De La Vigne Et Du Vin, 45(2), 61-73. https://doi.org/10.20870/oeno-one.2011.45.2.1488

Khaliq, A., Comba, L., Biglia, A., Ricauda Aimonino, D., Chiaberge, M., \& Gay, P. (2019). Comparison of satellite and UAV-based multispectral imagery for vineyard variability assessment. Remote Sensing, 11, 436. https://doi.org/10.3390/rs11040436

Kliewer, W. M., \& Dokoozlian, N. K. (2005). Leaf area/crop weight ratios of grapevines: Influence on fruit composition and wine quality. American Journal on Enology and Viticulture, 56(2), 170-181.

Kotsaki, E., Reynolds, A. G., Brown, R., Lee, H. S., \& Jollineau, M. (2019). Spatial variability in soil and vine water status in Ontario vineyards: Relationships to yield and berry composition. American Journal of Enology and Viticulture, 71(2), 132-148. https://doi.org/10.5344/ajev.2019.19019

Lorenz, D. H., Eichorn, K. W., Bleiholder, H., Klose, R., Meier, U., \& Weber, E. (1995). Phenological growth stages of the grapevine (Vitis vinifera L. Ssp vinifera) — codes and descriptions according to the extended BBCH scale. Australian Journal of Grape and Wine Research, 1(2), 100-103. https://doi.org/ 10.1111/j.1755-0238.1995.tb00085.x

Maes, W. H., \& Steppe, K. (2019). Perspectives for remote sensing with unmanned aerial vehicles in precision agriculture. Trends in Plant Science, 24, 152-154.

Marschner, H. (1995). Mineral nutrition of higher plants. Academic Press.

Matese, A., \& Di Gennaro, S. F. (2015). Technology in precision viticulture: A state of the art review. International Journal of Wine Research, 7, 69-81. https://doi.org/10.2147/IJWR.S69405

Matese, A., Toscano, P., Di Gennaro, S. F., Genesio, L., Vaccari, F. P., Primicerio, J., et al. (2015). Intercomparison of UAV, aircraft and satellite remote sensing platforms for precision viticulture. Remote Sensing, 7, 2971-2990. https://doi.org/10.3390/rs70302971

McBratney, A. B., Whelan, B. M., Ancev, T., \& Bouma, J. (2005). Future directions of precision agriculture. Precision Agriculture, 6(1), 7-23. https://doi.org/10.1007/s11119-005-0681-8

Miller, D. P., \& Howell, G. S. (1998). Influence of vine capacity and crop load on canopy development, morphology, and dry matter partitioning in concord grapevines. American Journal of Enology and Viticulture, 49, 183-190.

Miranda, C., Santesteban, L., Escalona, J., De Herralde, F., Aranda, X., Nadal, M., et al. (2017). Allometric relationships for estimating vegetative and reproductive biomass in grapevine (Vitis vinifera L.). Australian Journal of Grape and Wine Research, 23(3), 441-451. https://doi.org/10.1111/ajgw.12285 
Mori, K., Goto-Yamamoto, N., Kitayama, M., \& Hashizume, K. (2007). Loss of anthocyanins in red-wine grape under high temperature. Journal of Experimental Botany, 58(8), 1935-1945. https://doi.org/10. 1093/jxb/erm055

Morlat, R., \& Bodin, F. (2006). Characterization of viticultural terroirs using a simple field model based on soil depth-II. Validation of the grape yield and berry quality in the Anjou Vineyard (France). Plant and Soil, 281, 55-69. https://doi.org/10.1007/s11104-005-3769-z

Morlat, R., \& Jaquet, A. (1993). The soil effects on the grapevine root system in several vineyards of the Loire valley (France). Vitis, 32, 35-42.

Nogales-Bueno, J., Hernández-Hierro, J. M., Rodríguez-Pulido, F. J., \& Heredia, F. J. (2014). Determination of technological maturity of grapes and total phenolic compounds of grape skins in red and white cultivars during ripening by near infrared hyperspectral image: A preliminary approach. Food Chemistry, 152, 586-591. https://doi.org/10.1016/j.foodchem.2013.12.030

Pierce, F. J., \& Nowak, P. (1999). Aspects of precision agriculture. In D. L. Sparks (Ed.), Advances in agriculture (pp. 1-85). Academic Press.

Poni, S., Gatti, M., Palliotti, A., Dai, Z., Duchêne, E., Truong, T. T., et al. (2018). Grapevine quality: A multiple choice issue. Scientia Horticulturae, 234, 455-462. https://doi.org/10.1016/j.scienta.2017. 12.035

Priori, S., Pellegrini, S., Perria, R., Puccioni, S., Storchi, P., Valboa, G., et al. (2019). Scale effect of terroir under three contrasting vintages in the Chianti Classico area (Tuscany, Italy). Geoderma, 334, 99-112. https://doi.org/10.1016/j.geoderma.2018.07.048

Regione Emilia-Romagna. (2002). Descrizione delle osservazioni pedologiche (Description of Soil Observations). Servizio Geologico, Sismico e dei Suoli-Regione Emilia-Romagna, Bologna.

Regione Emilia-Romagna. (2018). I suoli dell'Emilia-Romagna (Soils of Emilia Romagna). Retrieved February 26, 2020, from https://geo.regione.emilia-romagna.it/cartpedo/.

Rey, C., Martin, M. P., Lobo, A., Luna, I., Diago, M. P., \& Millan, B., et al. (2013). Multispectral imagery acquired from a UAV to assess the spatial variability of a Tempranillo vineyard. In Stafford, J.V. (Ed.), Precision Agriculture '13. Proceedings of the 9th European Conference on Precision Agriculture (pp. 617-624). Wageningen Academic Publishers. https://doi.org/10.3920/978-90-8686

Salazar-Parra, C., Aranjuelo, I., Pascual, I., Aguirreolea, J., Sánchez-Díaz, M., Irigoyen, J. J., et al. (2018). Is vegetative area, photosynthesis, or grape $\mathrm{C}$ uploading involved in the climate changerelated grape sugar/anthocyanin decoupling in Tempranillo? Photosynthesis Research, 138(1), 115-128. https://doi.org/10.1007/s11120-018-0552-6

Savi, S., Poni, S., Moncalvo, A., Frioni, T., Rodschinka, I., Arata, L., et al. (2019). Destructive and optical non-destructive grape ripening assessment: Agronomic comparison and cost-benefit analysis. PLoS ONE, 14(5), e0216421. https://doi.org/10.1371/journal.pone.0216421

Saxton, K. E., Rawls, W. J., Romberger, J. S., \& Papendick, R. I. (1986). Estimating generalized soilwater characteristics from texture. Soil Science Society of America Journal, 50(4), 1031-1036. https://doi.org/10.2136/sssaj1986.03615995005000040039x

Smart, R. E. (1985). Principles of grapevine canopy microclimate manipulation with implications for yield and quality. A review. American Journal of Enology and Viticulture, 36, 230-239.

Smith, J. P., Edwards, E. J., Walker, A. R., Gouot, J. C., Barril, C., \& Holzapfel, B. P. (2019). A whole canopy gas exchange system for the targeted manipulation of grapevine source-sink relations using sub-ambient $\mathrm{CO}_{2}$. BMC Plant Biology, 19(1), 535.

Soil Survey Staff. (2014). Keys to soil taxonomy (twelfth). USDA-Natural Resources Conservation Service.

Squeri, C., Diti, I., Rodschinka, I. P., Poni, S., Dosso, P., Scotti, C., et al. (2021a). Is precision viticulture beneficial for the high-yielding Lambrusco (Vitis vinifera L.) grapevine district? American Journal of Enology and Viticulture. https://doi.org/10.5344/ajev.2021.20060

Squeri, C., Poni, S., Di Gennaro, S. F., Matese, A., \& Gatti, M. (2021b). Comparison and ground truthing of different remote and proximal sensing platforms to characterize variability in a hedgerowtrained vineyard. Remote Sensing, 13, 2056. https://doi.org/10.3390/rs13112056

Squeri, C., Gatti, M., Garavani, A., Vercesi, A., Buzzi, M., Croci, M., et al. (2019). Ground truthing and physiological validation of VIs-NIR spectral indices for early diagnosis of nitrogen deficiency in cv. Barbera (Vitis vinifera L.) Grapevines. Agronomy, 9(12), 864. https://doi.org/10.3390/agron omy9120864

Tardaguila, J., Baluja, J., Arpon, L., Balda, P., \& Oliveira, M. (2011). Variations of soil properties affect the vegetative growth and yield components of "Tempranillo" grapevines. Precision Agriculture, 12(5), 762-773. https://doi.org/10.1007/s11119-011-9219-4

Taylor, J. A., Dresser, J. L., Hickey, C. C., Nuske, S. T., \& Bates, T. R. (2019). Considerations on spatial crop load mapping. Australian Journal of Grape and Wine Research, 25(2), 144-155. https://doi. org/10.1111/ajgw.12378 
Tello, J., \& Ibáñez, J. (2014). Evaluation of indexes for the quantitative and objective estimation of grapevine bunch compactness. Vitis, 53(1), 9-16.

Tisseyre, B., Mazzoni, C., \& Fonta, H. (2008). Within-field temporal stability of some parameters in viticulture: Potential toward a site specific management. Journal International Des Sciences De La Vigne Et Du Vin, 42(1), 27-39. https://doi.org/10.2087/oeno-one.2008.42.1.834

Trought, M. C. T., \& Bramley, R. G. V. (2011). Vineyard variability in Marlborough, New Zealand: Characterising spatial and temporal changes in fruit composition and juice quality in the vineyard. Australian Journal of Grape and Wine Research, 17(1), 72-78. https://doi.org/10.1111/j.1755-0238.2010.00120.x

Trought, M. C. T., Dixon, R., Mills, T., Greven, M., Agnew, R., Mauk, J. L., et al. (2008). The impact of differences in soil texture within a vineyard on vine vigour, vine earliness and juice composition. Journal International Des Sciences De La Vigne Et Du Vin, 42(2), 62-72. https://doi.org/10.2087/ oeno-one.2008.42.2.828

Vaudour, E., Costantini, E., Jones, G. V., \& Mocali, S. (2015). An overview of the recent approaches to terroir functional modelling, footprinting and zoning. The Soil, 1, 287-312. https://doi.org/10.5194/ soil-1-287-2015

Verdugo-Vásquez, N., Acevedo-Opazo, C., Valdés-Gómez, H., Ingram, B., De Cortázar-Atauri, I. G., \& Tisseyre, B. (2018). Temporal stability of within-field variability of total soluble solids of grapevine under semi-arid conditions: A first step towards a spatial model. OENO One, 52(1), 15-30. https://doi.org/10. 20870/oeno-one.2018.52.1.1782

Vivin, P. H., Castelan, M., \& Gaudillère, J. P. (2002). A source/sink model to simulate seasonal allocation of carbon in grapevine. Acta Horticulturae, 584, 43-56. https://doi.org/10.17660/ActaHortic.2002.584.4

Williams, L. E., Dokoozlian, N. K., \& Wample, R. (1994). Grape. In B. Schaffer \& P. C. Andersen (Eds.), Handbook of environmental physiology of fruit crops. Temperate crops (Vol. 1, pp. 85-133). Boca Raton: CRC Press.

Willwerth, J. J., \& Reynolds, A. G. (2020a). Spatial variability in Ontario Riesling Vineyards: I. Soil, vine water status and vine performance. OENO One, 54, 327-350. https://doi.org/10.20870/oeno-one.2020. 54.2.2401

Willwerth, J. J., \& Reynolds, A. G. (2020b). Spatial variability in Ontario Riesling vineyards II Berry composition. Canadian Journal of Plant Science, 100(5), 504-527. https://doi.org/10.1139/cjps-2019-0291

Publisher's Note Springer Nature remains neutral with regard to jurisdictional claims in published maps and institutional affiliations. 